\title{
Material Transport in a Convective Surface Mixed Layer Under Weak Wind Forcing
}

\author{
Jean A. Mensa ${ }^{\mathrm{a}, *}$, Tamay M. Özgökmen ${ }^{\mathrm{a}}$, Andrew C. Poje ${ }^{\mathrm{b}}$, Jörg Imberger ${ }^{\mathrm{c}}$ \\ ${ }^{a}$ Department of Ocean Sciences, University of Miami, Florida, USA \\ ${ }^{b}$ Department of Mathematics, College of Staten Island, New York, USA \\ ${ }^{c} 43$ Goldsmith Rd, Dalkeith, Western Australia, 6009, Australia
}

\section{Abstract}

Flows in the upper ocean mixed layer are responsible for the transport and dispersion of biogeochemical tracers, phytoplankton and buoyant pollutants, such as hydrocarbons from an oil spill. Material dispersion in mixed layer flows subject to diurnal buoyancy forcing and weak winds $\left(\left|\boldsymbol{u}_{10}\right|=5 \mathrm{~ms}^{-1}\right)$ are investigated using a non-hydrostatic model. Both purely buoyancy-forced and combined wind- and buoyancy-forced flows are sampled using passive tracers, as well as 2D and 3D particles to explore characteristics of horizontal and vertical dispersion. It is found that the surface tracer patterns are determined by the convergence zones created by convection cells within a time scale of just a few hours. For pure convection, the results displayed the classic signature of Rayleigh-Benard cells. When combined with a wind stress, the convective cells become anisotropic in that the along-wind length scale gets much larger than the cross-wind scale. Horizontal relative dispersion computed by sampling the flow fields using both 2D and 3D passive particles is found to be consistent with the Richardson regime. Relative dispersion is an order of magnitude higher and 2D surface releases transition to Richardson regime faster in the wind-forced case. We also show that the buoyancy-forced case results in significantly lower amplitudes of scale-dependent horizontal relative diffusivity, $k_{D}(\ell)$, than those reported by Okubo (1970), while the wind- and buoyancy-forced case shows a good agreement with Okubo's diffusivity amplitude, and the scaling is consistent with Richardson's 4/3rd law, $k_{D} \sim \ell^{4 / 3}$. These modeling results provide a framework for measuring material dispersion by mixed layer flows in future observational programs.

8 Keywords: relative dispersion, scale-dependent diffusivity, upper ocean turbulence

\footnotetext{
*Corresponding author

Email address: jmensa@rsmas.miami.edu (Jean A. Mensa)
} 
The study of horizontal dispersion in the oceanic surface boundary layer (OBL) is of interest due to its importance in the dispersion of passive and active tracers, such as heat (Chelton et al., 2007), biogeochemical tracers (McGillicuddy and Robinson, 1998; Klein and Lapeyre, 2009; Mahadevan et al., 2012; Lévy et al., 2011; Machado and Imberger, 2013) and pollutants (Jernelöv and Lindén, 1981; Crone and Tolstoy, 2010; Poje et al., 2014). The OBL is also the home of much of the primary production that occurs in the upper ocean, sustained by surface sunlight, and the provision of nutrients via vertical mixing from underneath the photic zone (Lévy et al., 2001; McGillicuddy et al., 2007; Mahadevan et al., 2012). Hydrocarbons released during an oil spill tend to accumulate on the ocean's surface and interact with winds and ocean currents in ways that are dependent on the OBL dynamics (Reed et al., 1999; James, 2002; Tkalich, 2006).

In general, problems involving material transport require an accurate characterization of the underlying currents, that is made difficult in the ocean by the daunting challenges of sampling the wide range of the scales of mixing and transport processes involved (Sanford et al., 2011). Given the impossibility to sample all scales of motion in an Eulerian sense, several Lagrangian techniques have been developed to measure transport associated with a flow field (Rossby, 2007; Davis et al., 2008). Originally single-particle techniques (Taylor, 1921) were used to quantify diffusion in models and observations. These techniques were effective in determining the asymptotic behavior of dispersion at time scales that were often too long for practical applications of the transport problem. Two-particle statistics (Babiano et al., 1990; LaCasce, 2008), or relative dispersion, is more closely related to the synoptic turbulent nature of the underlying Eulerian dynamics (Batchelor, 1952; Bennett, 1984).

The fluid motion is constrained by rotation at the large transport scales, by the surface layer depth at intermediate scales and is fully three dimensional at the turbulent scales. Submesoscale motions are defined as those having scales below the deformation radius, ranging from about $10 \mathrm{~km}$ down to the typical depth of the mixed layer, on the order of $100 \mathrm{~m}$, where rotational control is still part of the dynamics (McWilliams, 
2008). One of the main questions about submesoscale motions is where in the ocean they exist and whether they have a transient nature. Numerical studies have shown that submesoscales were mostly confined to the OBL (Thomas et al., 2008; Capet et al., 2008; Fox-Kemper et al., 2008; Klein and Lapeyre, 2009; Taylor and Ferrari, 2010; Mensa et al., 2013). A recent field exploration revealed the existence of submesoscale flows in the upper ocean (Shcherbina et al., 2013). Numerical studies (Mensa et al., 2013; Sasaki et al., 2014) have indicated that submesoscales have a significant seasonal cycle becoming stronger in winter, as implied by the dependence of intensity of mixed layer instability on OBL depth (Boccaletti et al., 2007). Submesoscales are smaller and faster evolving than mesoscales, hence an important question is whether they contribute significantly to material dispersion in the ocean surface layer. This question was previously studied using numerical models (Haza et al., 2008; Poje et al., 2010; Özgökmen et al., 2011; Özgökmen and Fischer, 2012). A large upper ocean dispersion experiment conducted in the context of transport of surface oil in relation to a major spill event confirmed that submesoscales contribute to dispersion in the ocean (Poje et al., 2014). At scales where rotational control breaks down, transition to 3D structures would appear to occur at the depth of the surface layer with the emergence of Langmuir turbulence (Langmuir, 1938; Craik and Leibovich, 1976; Skyllingstad and Denbo, 1995; McWilliams et al., 1997; Thorpe, 2004; D'Asaro, 2014). These cells are well-defined coherent structures, the result of Stokes effect from non-breaking surface waves, with lines of convergence aligned in the direction of the wind.

Ultimately the OBL presents, arguably, the largest collection of processes ranging from micro turbulent scales of millimeters or less, convective plumes and fronts driven by surface buoyancy forcing, restratification via submesoscale eddies, 3D motions by Langmuir circulations, vertical shears arising from Ekman spiral, Stokes drift exerted by surface waves, and turbulent stirring via mesoscale eddies underneath the mixed layer.

Both modeling and observations of fluid flow in the OBL pose major challenges. This is because none of the ocean processes exists in isolation, and smaller scale processes typically last for shorter periods. Therefore it is quite difficult to assess their individual roles 
in the presence of multi-scale interactions spanning a wide range. Most of the numerical models developed by the oceanographic community solve the hydrostatic primitive equations using a closure scheme for sub-grid scales. However, scales smaller than submesoscales require non-hydrostatic models with high spatial resolution matching the scales of the motions. Non-hydrostatic solvers are computationally expensive (Scotti and Mitran, 2008) and hybrid hydrostatic/non-hydrostatic methods (Botelho et al., 2009) have emerged to handle simultaneously different classes of oceanic flows during a simulation. From the point of view of the observations, only few instruments exist that can sample the mixed layer across the above range of scale in 3D. The coherent structures, at the scale larger than the depth of the surface layer, have been documented with Lagrangian floats (D'Asaro and Farmer, 1996; D'Asaro et al., 2011) and the scales from the turbulence microstructure $(<1 \mathrm{~mm})$ to the depth of the surface layer have been documented with the Portable Flux Profiler (Machado and Imberger, 2013).

There have been a number of studies conducted to explore the dynamics of the OBL. Skyllingstad and Denbo (1995) carried out the first large eddy simulations (LES, modeling approach in between the direct numerical simulation where all of turbulence is resolved and Reynolds averaged Navier Stokes where all turbulence is parameterized) in order to capture the finite-amplitude behavior of unstable Langmuir modes that had been investigated analytically thus far (e.g., Leibovich and Tandon (1993)). Results showed that Langmuir turbulence enhanced vertical circulation within the OBL under a variety of wind and buoyancy forcing conditions, and this finding stimulated further studies (e.g., McWilliams et al. (1997)). McWilliams and Sullivan (2000) noted that Langmuir turbulence implies a need for parameterizations of mixing in models that do not resolve these motions. D'Asaro (2001) showed that vertical turbulent kinetic energy magnitude is higher in the ocean boundary layer than in solid-wall boundary layers with the same applied wind stress due to the waves and Langmuir circulations. Kukulka et al. (2010) demonstrated by comparing LES to observations that Langmuir circulations are important not only near the surface, but also for entrainment at the base of the OBL. Belcher et al. (2012) stressed the importance of Langmuir turbulence for getting the OBL depth 
right in global models and D'Asaro et al. (2014) quantified the contribution of Langmuir turbulence to global mixed layer depth. Given the importance of Langmuir turbulence for vertical momentum fluxes in the OBL, Harcourt (2013) developed a second-order turbulence closure specifically for these processes. Enhanced dissipation in the OBL is not only caused by Langmuir circulation, but submesoscale fronts also play a role through symmetric instability (D'Asaro et al., 2011).

Despite these investigations focussing on the dynamics and dissipation in the OBL, only few studies have been conducted on how the OBL circulation impacts dispersion of material, which is of great importance for applied problems discussed above. Özgökmen et al. (2011, 2012); Özgökmen and Fischer (2012) simulated OBL using LES and sampled with tracers and particles. Nevertheless, these mixed layer flows were not forced by the atmosphere, but only internally by restratification of submesoscale fronts. Motivated by a large oil spill, Yang et al. (2014) explored the surface signature of pollutants as a function of the rise velocity of oil droplets and downwelling and dilution due to Langmuir cells.

Here, we conduct a study on dispersion in the OBL forced by regular buoyancy fluxes and weak winds. Flow patterns under weaker wind conditions have not been subject to extensive investigation even though they characterize the ocean state over large spatiotemporal scales. Here, Langmuir circulations are not considered for simplicity (but certainly deserve future work). Harcourt and D'Asaro (2008) emphasized that not only a monochromatic wave, but a spectrum of wave forcing was needed to get realistic results. Van Roekel et al. (2012) showed that any misalignment between the direction of winds and waves can substantially change the Langmuir circulation. Therefore, by including the Langmuir turbulence, the parameter space and the complexity of the problem increase substantially. Besides, D'Asaro et al. (2014) show that Langmuir turbulence is not important everywhere in the ocean. Also, in a recent study of tracer injected in the OBL, lidar observations of banded structures were qualitatively reproduced using LES both with and without the Langmuir forcing (Sundermeyer et al., 2014). We also do not consider submesoscale fronts or mesoscale eddies in deeper layers in this study; again for reasons of simplicity. Certainly, these features must influence transport in the OBL, yet 
inclusion of both Langmuir cells and submesoscale fronts (Hamlington et al., 2014) or submesoscale fronts and mesoscale eddies (Özgökmen and Fischer, 2012) is computationally very demanding at the present time, and getting all three resolved in the computational domain is not yet feasible. Our study is similar to the one by Heitmann and Backhaus (2005), in which the characteristics of buoyancy and wind forced flows in a similar setup as our simulations were investigated (for the Arctic Ocean). The main difference from the study conducted by Heitmann and Backhaus (2005) is that, here the main focus is on horizontal and vertical material dispersion using Lagrangian methods.

The objectives of this study are to address the following questions:

a) Which processes characterize flows driven by moderate winds speeds of $\left|\boldsymbol{u}_{\mathbf{1 0}}\right|=$ $5 \mathrm{~ms}^{-1}$, or less, and diurnal buoyancy forcing in the ocean mixed layer?

b) How do these dynamical processes determine horizontal dispersion? How do these results compare to canonical scaling laws, e.g. those by Richardson (1926) and Okubo (1970)?

c) When these flows are sampled by more traditional and readily available near-surface 2D drifters, as opposed to fully Lagrangian 3D floats, what types of differences can be noted in relative dispersion and scale-dependent diffusivity?

The paper is structured as it follows. In section 2, the numerical model and experiments are described. The goal is to explore two regimes: a case of pure convection and one of mixed of buoyancy and wind-forcing. In section 3, the general dynamics are described, while in section 4 , we focus on material transport, including comparison to scaling laws and previous findings. The main advances in our understanding are summarized in section 5 .

\section{Method}

We use the finite element Boussinesq equation solver Fluidity-ICOM (Imperial College Ocean Model, Piggott et al. (2008)) and apply it to a $8 \mathrm{~km} \times 8 \mathrm{~km} \times 50 \mathrm{~m}$ domain, to represent a section of OBL with both convective and wind stress forcing. 


\subsection{Numerical model and configuration}

Fluidity-ICOM was configured to integrate the following equations:

$$
\begin{aligned}
\frac{D \boldsymbol{u}}{D t}+2 \boldsymbol{\Omega} \times \boldsymbol{u} & =-\frac{1}{\rho_{0}} \nabla p^{\prime}+\rho^{\prime} \boldsymbol{g}+\nabla \cdot \boldsymbol{\nu} \nabla \boldsymbol{u}, \\
\nabla \cdot \boldsymbol{u} & =0, \\
\frac{D T}{D t} & =\nabla \cdot(\boldsymbol{k} \nabla T)+\frac{F_{T}}{\rho_{0} C_{p}}, \\
\frac{D C}{D t} & =\nabla \cdot(\boldsymbol{k} \nabla C),
\end{aligned}
$$

where $D / D t=\frac{\partial}{\partial t}+\boldsymbol{u} \cdot \nabla$ is the total derivative operator, $\boldsymbol{u}=(u, v, w)$ is the velocity vector, $\boldsymbol{\Omega}$ is the planetary angular velocity vector defined as $\Omega=(0,0, f / 2)$ with $f=$ $10^{-4} s^{-1}$ being the Coriolis parameter, $p^{\prime}$ is the dynamic pressure, $\boldsymbol{g}=(0,0,-g)$ with $g$ being the gravitational acceleration, $T$ is the temperature, $C$ is a passive scalar field, $\boldsymbol{\nu}=\left(\nu_{h}, \nu_{h}, \nu_{z}\right)$ with $\nu_{h}=5 \times 10^{-2} m^{2} s^{-1}, \nu_{z}=5 \times 10^{-4} m^{2} s^{-1}$ and $\boldsymbol{k}=\left(k_{h}, k_{h}, k_{z}\right)$ with $k_{h}=5 \times 10^{-2} m^{2} s^{-1}, k_{z}=5 \times 10^{-5} m^{2} s^{-1}$ were respectively the kinematic viscosity and thermal diffusivity vectors. The diffusivity and viscosity values are chosen in order to remove sub-grid noise, thus representing an upper bound of the diffusivities induced by unresolved processes.

The modeling approach presented here focuses on the scales between the semi-3D dynamics of the submesoscale range and the fully 3D dynamics of the inertial range. For this reason we focus our effort on resolving convection and shear more than small scale turbulence developing at higher Reynolds numbers as these are the processes thought to dominate dispersion and stirring at these scales.

By using a non-hydrostatic model, Reynolds stresses created by resolved motions, such as convective plumes, result in larger effective diffusivities than those selected above. $F_{T}$ is the surface heat flux forcing, and $C_{p}=4000 \mathrm{~J} \mathrm{Kg}^{-1} \mathrm{~K}^{-1}$ is the specific heat capacity. The perturbation density $\rho^{\prime}$ in $\rho=\rho_{0}+\rho^{\prime}$ is expressed through a linear equation of state that depends only on temperature: $\rho=\rho_{0}\left[1-\alpha\left(T-T_{0}\right)\right]$, where the reference density is $\rho_{0}=1027 \mathrm{Kg} \mathrm{m}^{-3}$, thermal expansion coefficient is $\alpha=1.5 \times 10^{-4}{ }^{\circ} \mathrm{C}^{-1}$, and reference temperature is $T_{0}=10^{\circ} \mathrm{C}$. The vortex force used to parameterize the wind- 
wave effect, which is thought to generate Langmuir circulations (Craik and Leibovich, 1976) is neglected in this study on the basis of weak winds (see Eq. 6) and for simplicity.

\begin{tabular}{l|c|c|c|c|c|c}
$\operatorname{Exp}$ & $L_{x}, L_{y}[\mathrm{~km}]$ & $\mathrm{H}[\mathrm{m}]$ & $\Delta x[\mathrm{~m}]$ & $\Delta z[\mathrm{~m}]$ & Forcing & Integration Time \\
\hline$B$ & 8,8 & 50 & 25 & $1-2$ & Buoyancy only & 10 days \\
\hline$B W$ & 8,8 & 50 & 25 & $1-2$ & Buoyancy and wind & 10 days
\end{tabular}

Table 1: Domain and mesh sizes in the numerical experiments. $L_{x}, L_{y}$ and $H$ are the horizontal and vertical domain sizes, $\Delta x$ and $\Delta z$ are the horizontal and vertical mesh sizes. The initial vertical temperature profile and the diurnal variability of the forcing are shown in Figure $1 \mathrm{a}$ and $1 \mathrm{c}$.

Discretization in Fluidity-ICOM is based on a first-order discontinuous Galerkin approximation for tracers and momentum, and second-order continuous Galerkin representation for pressure (Cotter et al., 2009). The model is capable of adaptive (moving) meshes, but here the mesh was fixed; it is unstructured in the horizontal, and structured in the vertical (elements were vertically aligned).

In the horizontal, the element size was $25 \mathrm{~m}$ while the vertical layers were evenly spaced every $1 \mathrm{~m}$ in the upper $20 \mathrm{~m}$ and every $2 \mathrm{~m}$ near the bottom. The boundary conditions at the side boundaries were periodic. No volume/heat flux and no-slip conditions were used at the bottom. The top boundary has a free-surface condition described in Kramer et al. (2010) forced by wind stress and the surface heat flux. A Neumann boundary condition for temperature was applied to the top boundary as part of the buoyancy forcing.

The simulations were initialized from rest with an idealized temperature profile with weak stratification in the first $45 \mathrm{~m}$ and a stronger stratification near the bottom (Figure 1a). The mixed layer did not contain density fronts initially, nor was it subjected to mesoscale strain. Therefore, all processes other than those generated by the uniform surface forcing were excluded in this study.

The computations were conducted on 512 cores of a recent IBM cluster at the University of Miami. The ratio of simulated to wall clock time ratio was approximately two. 


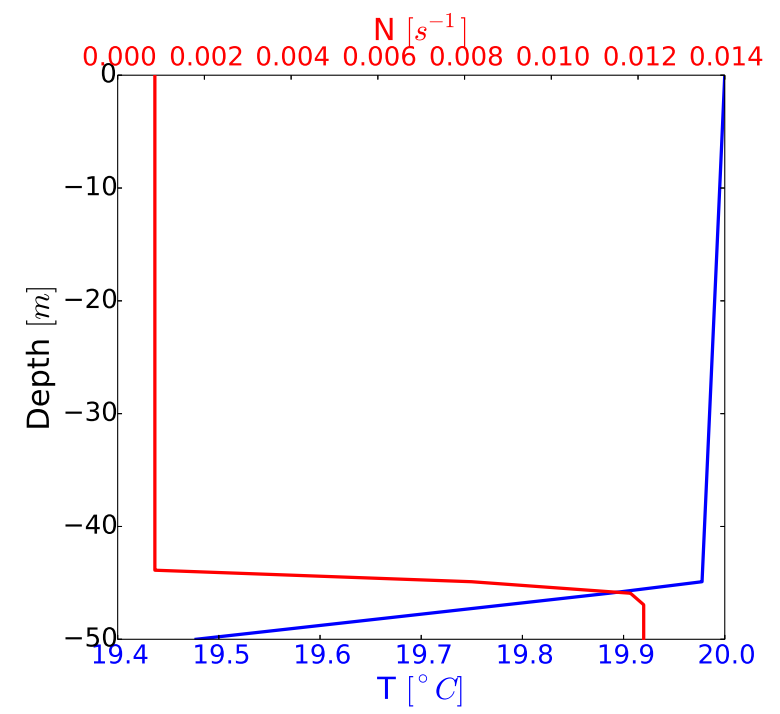

(a)

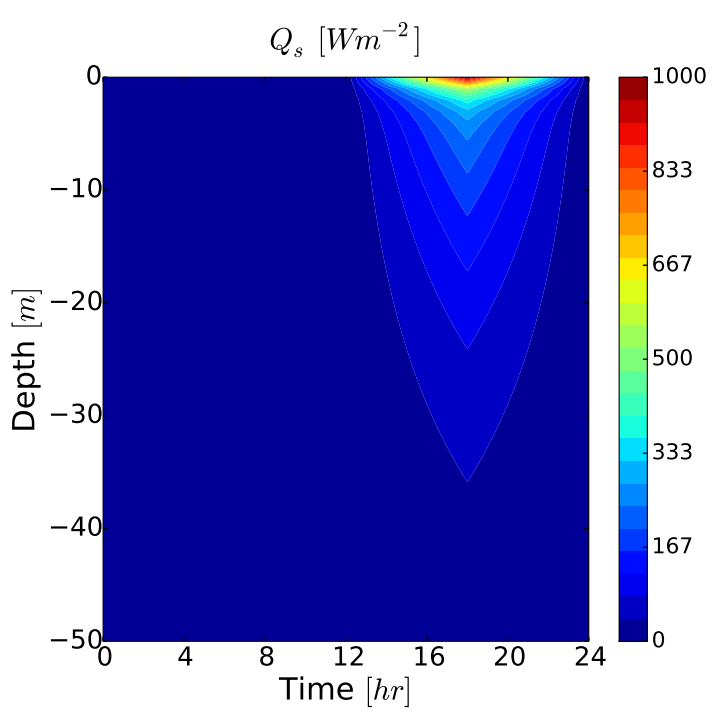

(b)

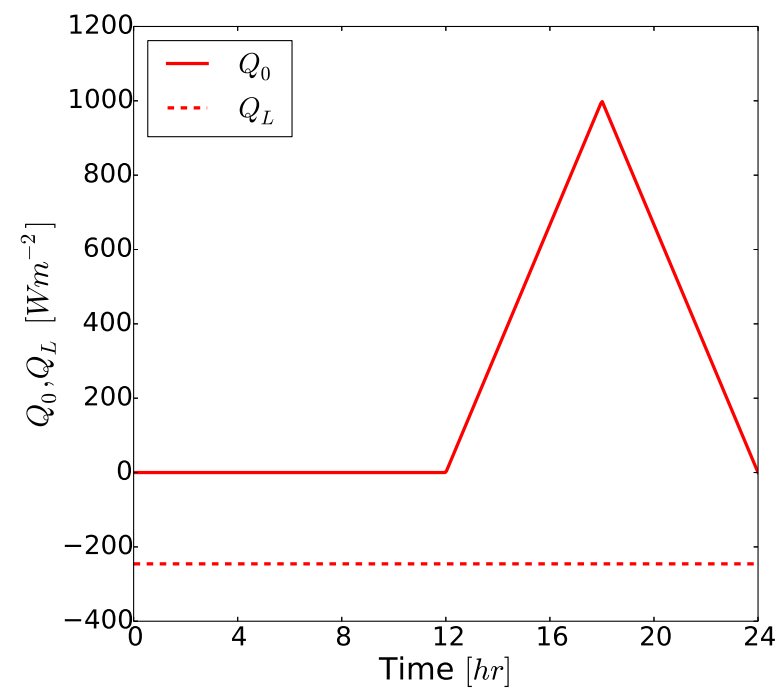

(c)

Figure 1: (a) The initial condition for temperature (blue) and the corresponding Brunt-Väisälä frequency $N$ (red). (b) Daily cycle of penetrating short wave radiation $Q_{s}$. Cooling at the surface is constant in time and balances the short wave radiation. (c) Daily cycle of short wave radiation at the surface $Q_{0}$ (solid) and long wave radiation $Q_{L}$ (dashed). 
The first term on the right hand side of equation (2) represents the surface fluxes due to infrared radiation, sensible and latent heat defined at the water surface following Large and Yeager (2004)

$$
\overline{w T}=Q_{L},
$$

where $Q_{L}$ is the outgoing long wave radiation, that is assumed negative (corresponding to surface cooling) and constant in time, since its variations are small over the time scale of the simulation period (Price et al., 1986) (Figure 1c).

The second term on the right hand side of equation (2) represents the heating due to short wave radiation $Q_{s}(z, t)$, that varied on a diurnal cycle. The depth of penetration of the short wave radiation depends on water turbidity, and was parameterized as described by Paulson and Simpson (1977)

$$
Q_{s}(z, t)=Q_{0}(t)\left(R e^{z / \beta_{1}}+(1-R) e^{z / \beta_{2}}\right),
$$

where $Q_{0}(t)$ is the magnitude of the short wave surface radiation at the surface (Figure 1c) and $R$ is the short wave absorption coefficient. The parameters $\beta_{1}, \beta_{2}$ and $\mathrm{R}$ depend on the turbidity of the mixed layer. Here, the mixed layer was assumed to contain Type 1B water according to the classification of Jerlov (1968). This corresponds to a relatively clear mixed layer with values of $R=0.67, \beta_{1}=1.0$ and $\beta_{2}=17$. The daily cycle of $Q_{0}(t)$ is not a simple sinusoidal, but was taken to mimic the observations recorded by Price et al. (1986) and Brainerd and Gregg (1995). The daily cycle of $Q_{0}$ was implemented in the model as

$$
\begin{array}{lrr}
Q_{0}=0 ; & 0<t<12 h \quad \text { (Morning) } \\
Q_{0}=Q_{\text {Max }}\left(\frac{t-12}{6}\right) ; & 12<t<18 h \quad(\text { Afternoon }) \\
Q_{0}=Q_{\text {Max }}-Q_{\text {Max }}\left(\frac{t-18}{6}\right) ; & 18<t<24 h \quad \text { (Evening) }
\end{array}
$$

where $Q_{\text {Max }}=1000 \mathrm{Wm}^{-2}$ and $t$ is model time in hours. The resulting profile of $Q_{s}(z, t)$ is plotted in Figure 1b. The net heating was assumed to be zero. Thus from (2) the 
resulting surface heat flux, assuming no flux at the bottom boundary, was equal to $Q_{L}=$ $-245.64 \mathrm{Wm}^{-2}$. This value is within the observed range in the ocean (Gregg, 1989).

Two distinct simulations were executed; Exp. $B$ where the wind stress was set to zero and Exp. $B W$, where a wind forcing was applied at the water surface in form of a stress vector $\boldsymbol{\tau}=\left(\tau_{x}, \tau_{y}\right)$ (applied as a boundary condition in the model),

$$
\boldsymbol{\tau}=\rho_{a} C_{D}\left|\boldsymbol{u}_{10}\right| \boldsymbol{u}_{10},
$$

where $\rho_{a}=1.3 \mathrm{Kgm}^{-3}$ is the air density, $C_{D}=1.5 \times 10^{-3}$ is the drag coefficient for the assumed neutral meteorological boundary layer and $\boldsymbol{u}_{\mathbf{1 0}}$ is the wind velocity vector. Wind was assumed zonal with a magnitude of $\left|\boldsymbol{u}_{\mathbf{1 0}}\right|=5 \mathrm{~ms}^{-1}$ and constant in time. This corresponds to a state with relatively calm winds, typically generating a surface oceanic current on the order of $0.1 \mathrm{~ms}^{-1}$ (Hunkins, 1966; Price et al., 1987).

\section{Description}

\subsection{Buoyancy-driven mixed layer flows}

In Exp. $B$, the diurnal heat flux, shown in Figure $1 \mathrm{~b}$ and $1 \mathrm{c}$, generated alternating phases of stronger and weaker convection. The simulations were commenced at midnight from the state of weak stratification, shown in Figure 1a. In the horizontal, the surface plumes were organized into polygons, similar to those observed in laboratory experiments (Veronis, 1959; Grooms et al., 2010). Forced by the surface cooling, plumes quickly developed and grew in time in the form of a classic Rayleigh-Benard instability (Rossby, 1969; Jones and Marshall, 1993; Bodenschatz et al., 2000; Grooms et al., 2010). Similar cellular structures were observed by Marmorino et al. (2009) in the field at low winds, using airborne remote sensing.

After 12 hours, the plume structure was already fully developed as seen in Figure 2a. At noon, the short wave radiation started to heat the water column suppressing convection. During the second and successive cycles of the surface buoyancy forcing, the mixed layer was not quiescent at the commencement of the cycle, thus plumes did not develop uniformly, but preferentially at locations where the stratification was weaker 


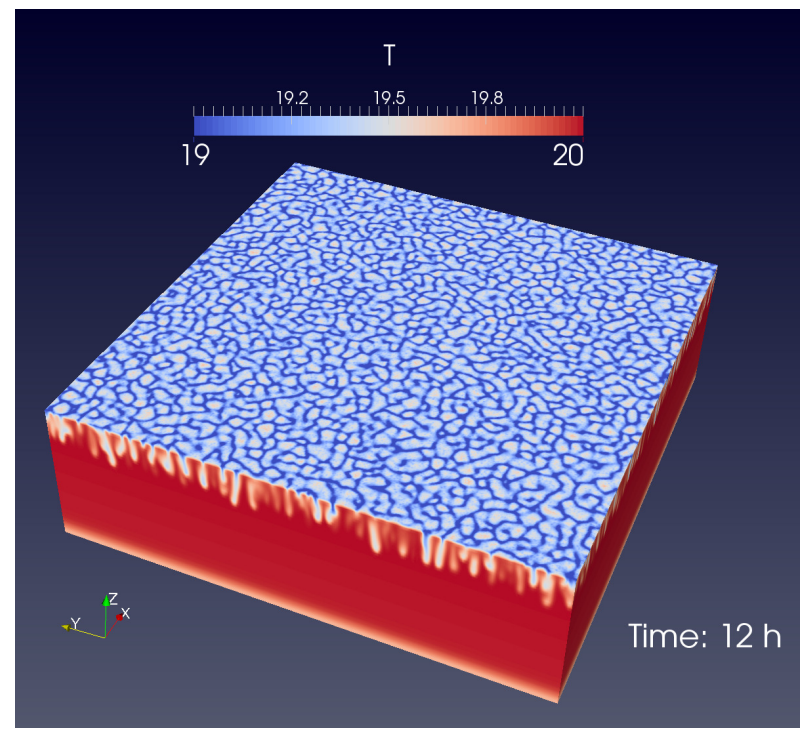

(a)

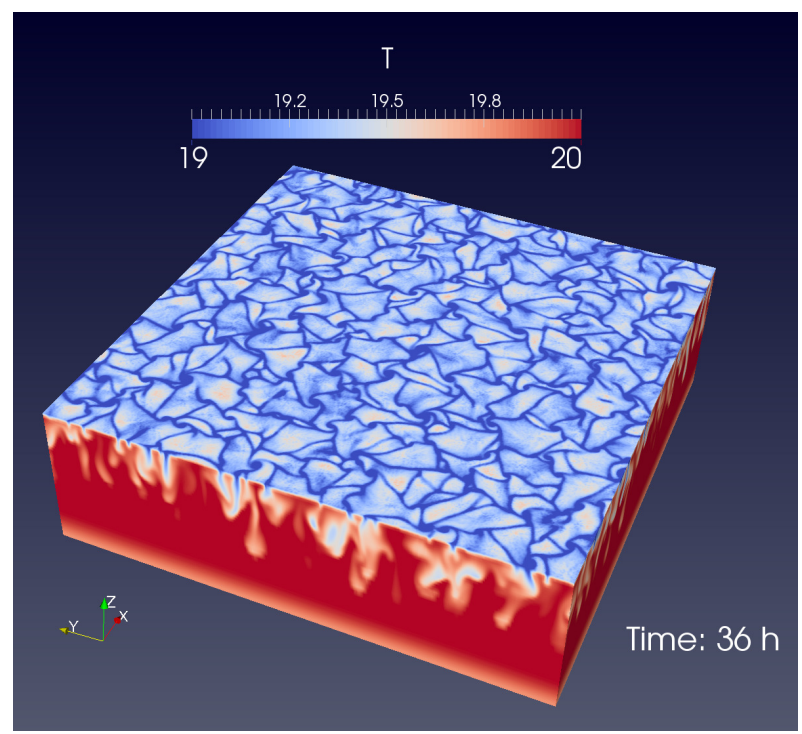

(c)

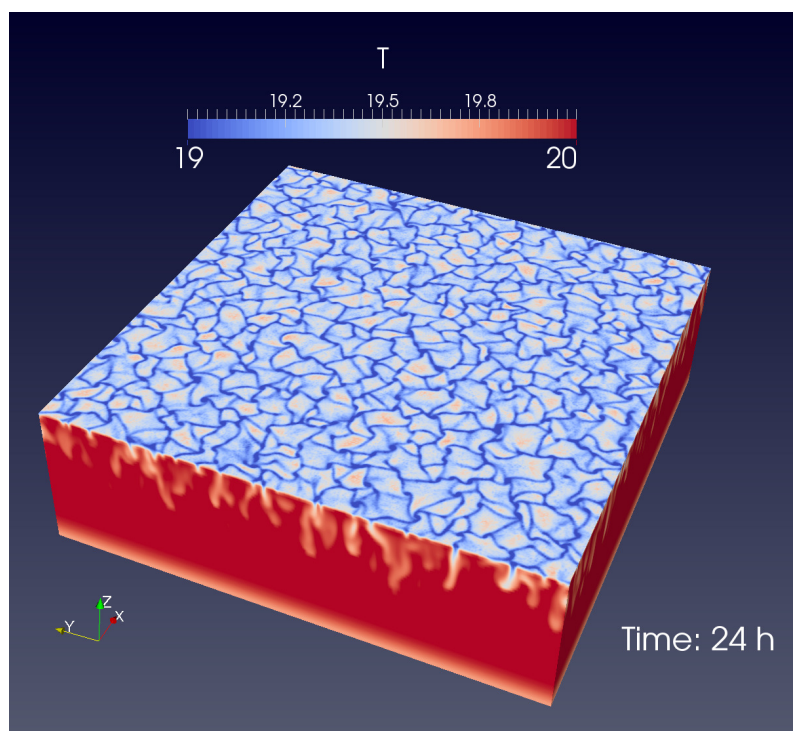

(b)

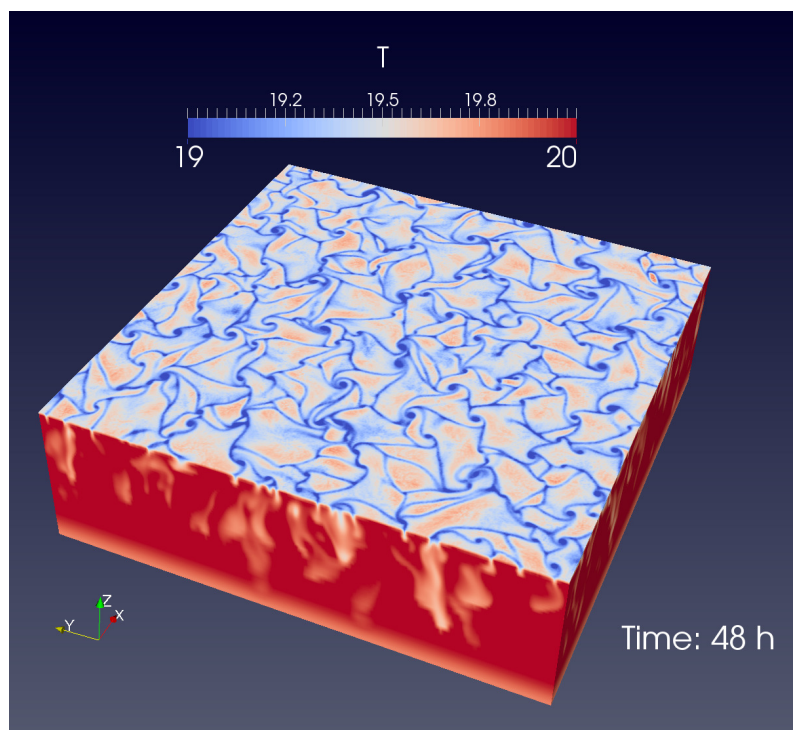

(d)

Figure 2: Temperature field for Exp. $B$ during the first two convective cycles: at the beginning of the surface heating ((a) at 12 hours and (c) at 36 hours) and at the end of the cycle of surface buoyancy forcing ((b) at 24 hours and (d) at 48 hours). The animation is available from: http://youtu.be/QtOrKF2z2gw. whether the spatial scale of these cells is rotationally controlled. The theoretical horizontal scale of the cells in rotating convection $l_{\text {conv }}$ is given by (Jones and Marshall, 
1993),

$$
l_{\text {conv }}=\sqrt{\frac{B_{0}}{f^{3}}},
$$

where the buoyancy flux $B_{0}$ can be expressed as,

$$
B_{0}=\frac{g \alpha Q_{L}}{\rho C_{p}} .
$$

For our setting, we get a value of $B_{0}=0.87 \times 10^{-7} \mathrm{~m}^{2} \mathrm{~s}^{-3}$ and a corresponding $l_{\text {conv }}=$ $295 \mathrm{~m}$.

The sizes of the cells in Exp. $B$ are quantified using a peak detection algorithm that identifies the colder regions at the cell boundaries. This algorithm is applied to zonal sections of the sea surface temperature and basic statistics are computed. Results in Table 2 show a reasonable agreement with the theoretical value of $l_{\text {conv }}=295 \mathrm{~m}$, indicating rotational control over cell size. Also, we note that horizontal model resolution of $25 \mathrm{~m}$ is adequate to resolve these features.

\begin{tabular}{c|c|c|c|c} 
Time $[h]$ & mean size $[m]$ & $\min$ size $[m]$ & $\max$ size $[m]$ & std $[m]$ \\
\hline 12 & 224 & 186 & 266 & 19 \\
\hline 24 & 246 & 173 & 320 & 28 \\
\hline 36 & 264 & 205 & 380 & 37 \\
\hline 48 & 272 & 195 & 380 & 39 \\
\hline 60 & 234 & 167 & 307 & 31 \\
\hline 72 & 234 & 170 & 400 & 36
\end{tabular}

Table 2: Cell size statistics in Exp. $B$ for different times.

\subsection{Buoyancy and wind-driven mixed layer flows}

As seen in Figure 3, the combined wind-forced convective surface mixed layer in Exp. $B W$ also exhibited phases of strong convection, with the surface signature of the convective plume structure becoming elongated to the right of the direction of the wind. Further, the plumes were sheared in the vertical.

During the convective phase of $\operatorname{Exp} B W$, horizontal jet-like structures were observed to be associated with the down welling regions (Figure 4a). These jet like structures corresponds to regions of convergence with increased vertical velocity (Fig. 4b); the 


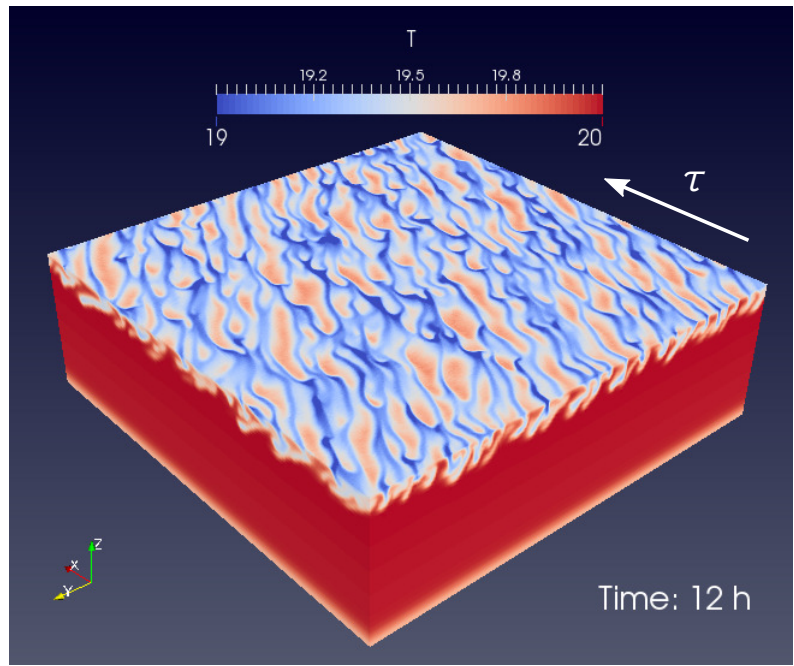

(a)

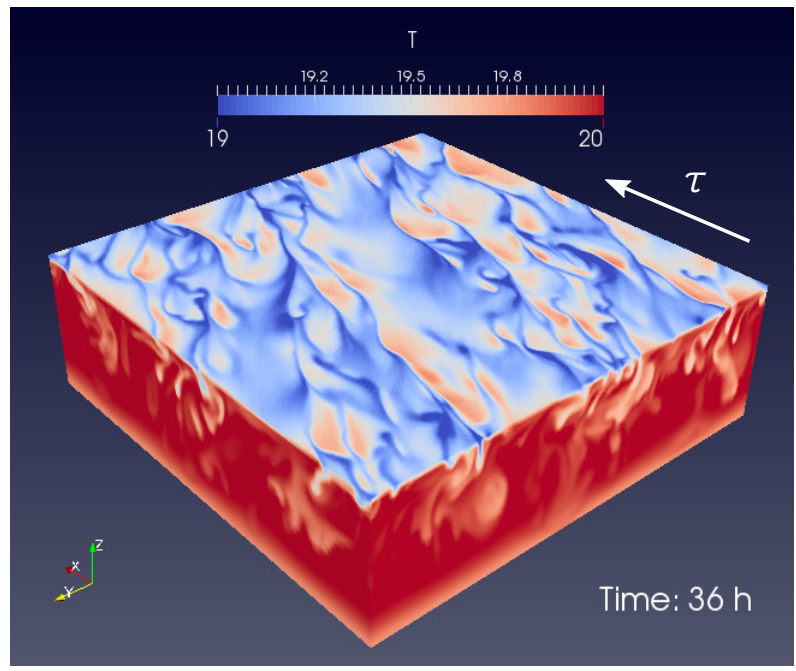

(c)

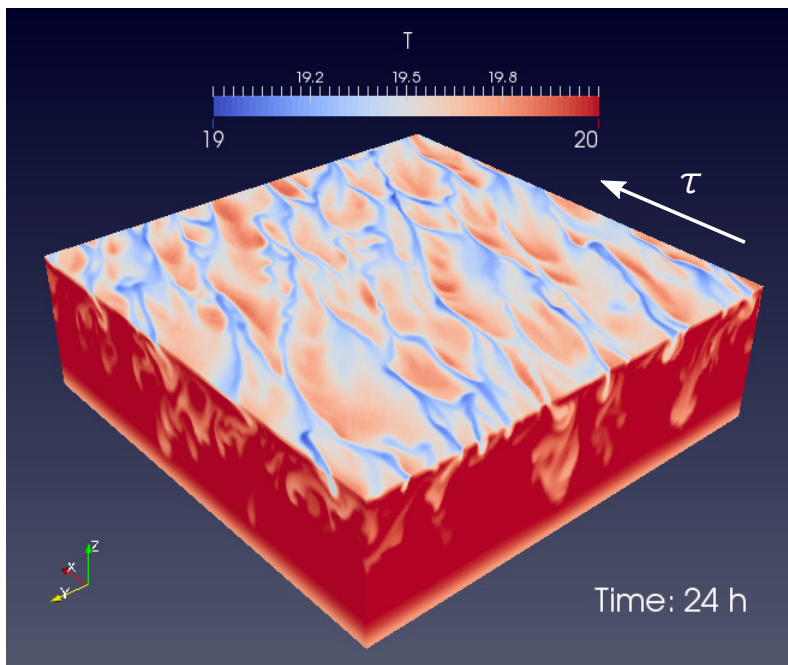

(b)

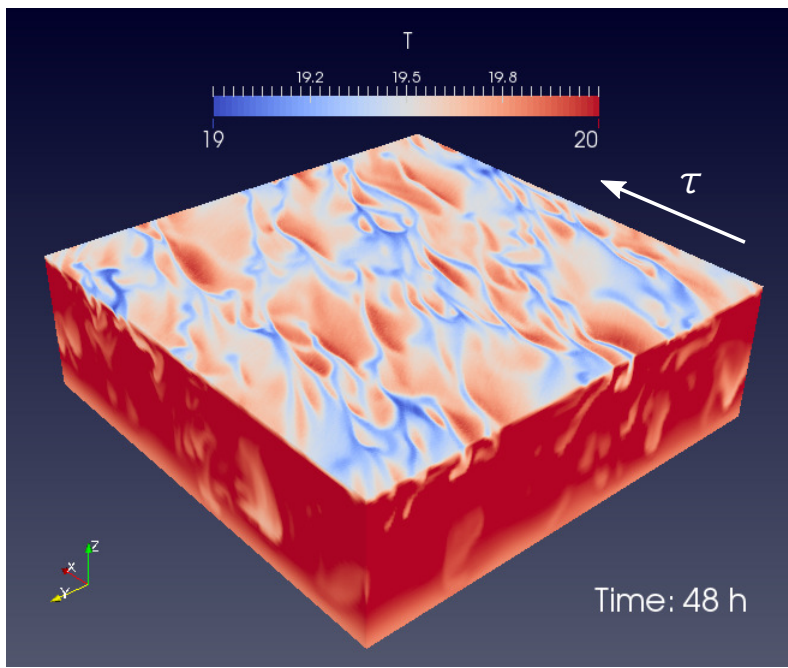

(d)

Figure 3: Temperature field in Exp. $B W$ (a) after 12 hours, during the first cooling event, (b) after 24 hours, at the end the first day, (c) at 36 hours during the second cooling event and (d) at 48 hours at the end of the second day. The white arrow shows the wind stress direction. The animation is available from: http://youtu.be/TYYI6VvB34Y.

Similar flows have been generated by Moeng and Sullivan (1994) in a model of the atmospheric boundary layer and by Heitmann and Backhaus (2005) in a model of the oceanic surface mixed layer. Airborne remote sensing images by Marmorino et al. (2009) and in-situ observations by Soloviev (1990) also detected downwelling structures features at the ocean's surface. 


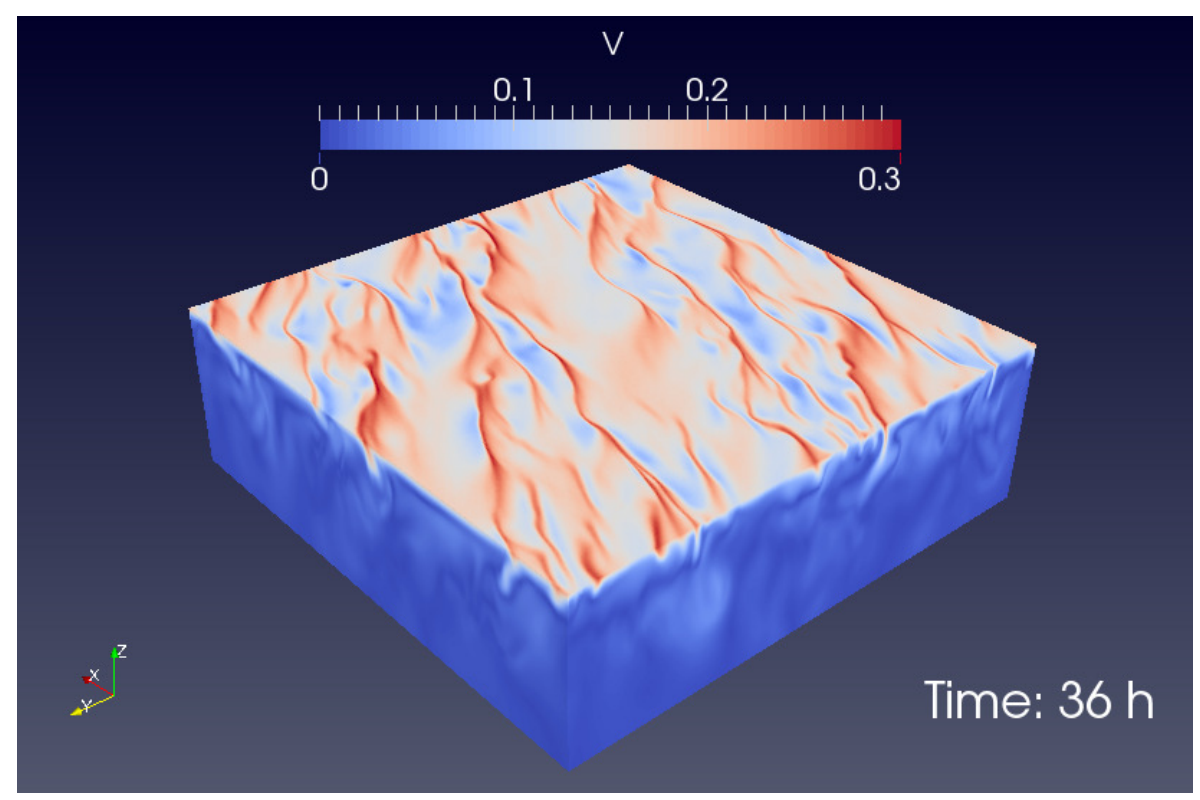

(a)

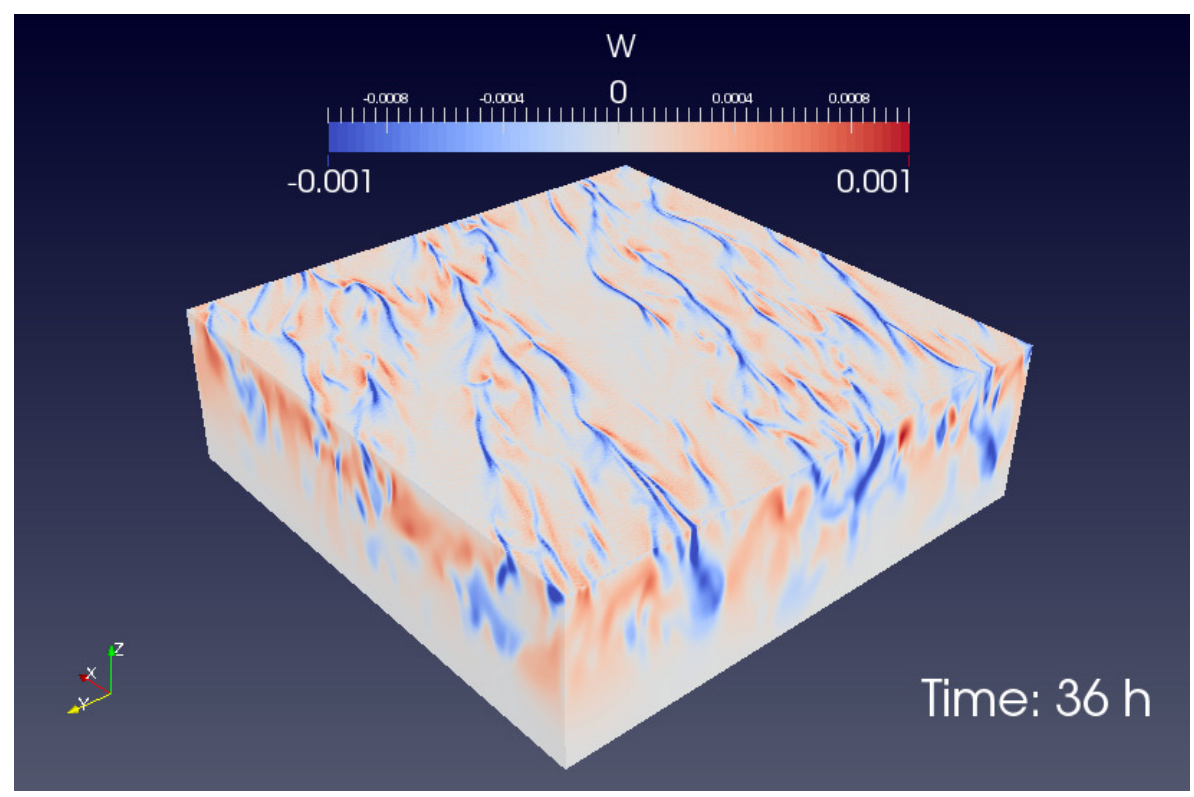

(b)

Figure 4: (a) Horizontal speed $\left[\mathrm{m} \mathrm{s}^{-1}\right]$ and (b) vertical velocity $\left[\mathrm{m} \mathrm{s}^{-1}\right]$ at the end of the second convective event (at 36 hours) in Exp. $B W$.

In Exp. $B W$ after about 72 hours Coriolis forces arrested the turning of the flow particle trajectories advected with the horizontally-averaged velocities at different depths. Trajectories show larger velocities near the surface, turning to the right with depth and inverting direction at approximately $20 \mathrm{~m}$ depth, consistent with Ekman theory.

The Ekman spiral was observed to oscillate with a frequency corresponding to the 


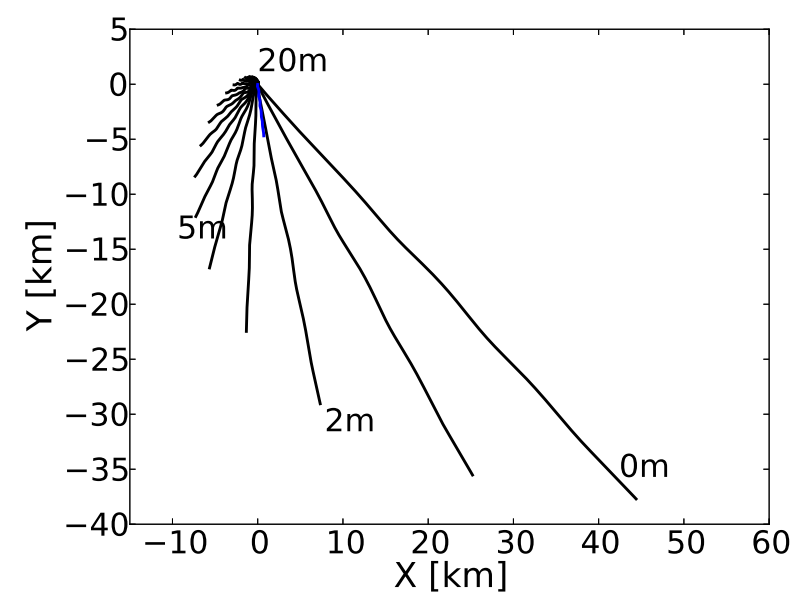

(a)

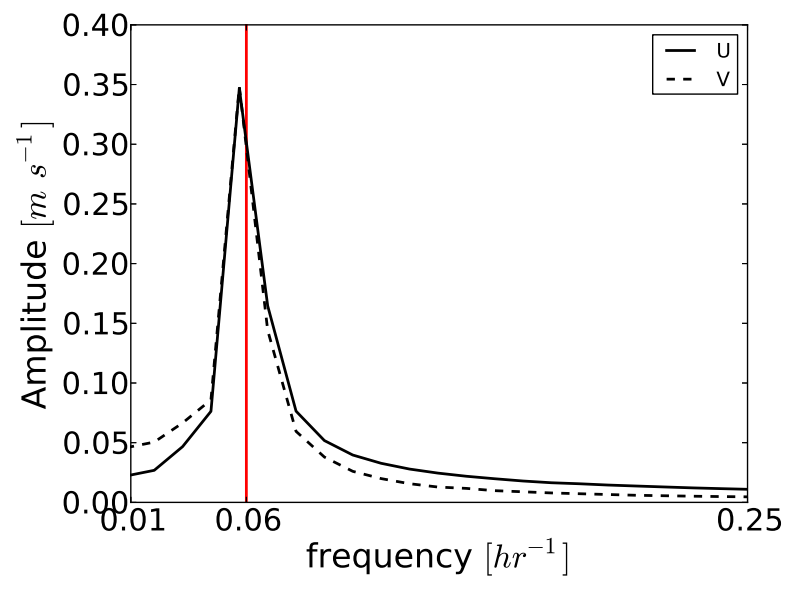

(b)

Figure 5: (a) Ekman spiral visualized from particle trajectories advected with the horizontally domain-averaged velocities at different depths in Exp. $B W$. (b) The frequency spectrum of the zonal (solid) and meridional (dashed) velocities showing a maximum at the inertial frequency (red line).

Domain-averaged horizontal and vertical velocity magnitude are computed as follows and their temporal evolutions are shown in Figure 6,

$$
\langle|\mathbf{u}|\rangle=\frac{1}{N_{x} N_{y} N_{z}} \sum_{i, j, k}^{N x, N y, N z} \sqrt{u_{i, j, k}^{2}+v_{i, j, k}^{2}} ; \quad\langle|w|\rangle=\frac{1}{N_{x} N_{y} N_{z}} \sum_{i, j, k}^{N x, N y, N z}|w|_{i, j, k}
$$

where $N_{x}, N_{y}$ and $N_{z}$ are the number of grid points in the horizontal and vertical directions. We notice that $\langle|\mathbf{u}|\rangle$ is an order of magnitude larger in Exp. $B W$ than that in Exp. $B$ due to wind forcing. Vertical velocity magnitude is affected by convective motions modulated by the diurnal cycle of the surface buoyancy forcing. Very little difference in $\langle|w|\rangle$ is observed between Exps. $B$ and $B W$ after the 72 hours mark. Vertical flows are thus mainly driven by convection in both experiments, while the near-surface horizontal velocity in Exp. $B W$ field was determined mostly by wind. By visual inspection of the time series shown in Figure 6, a spin-up time of 72 hours was selected, and most of the diagnostics in the rest of paper were computed after this time. 


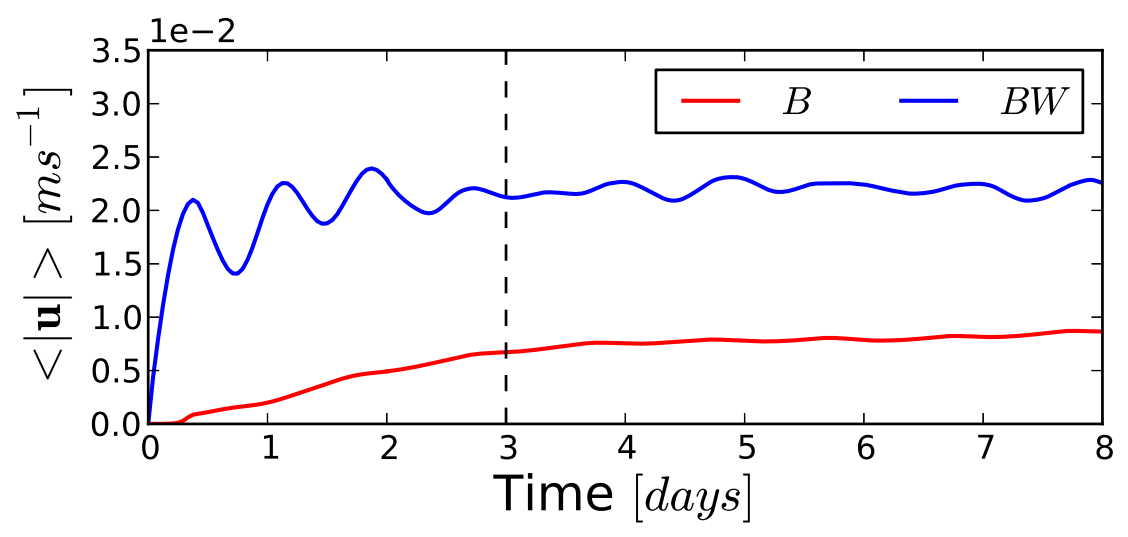

(a)

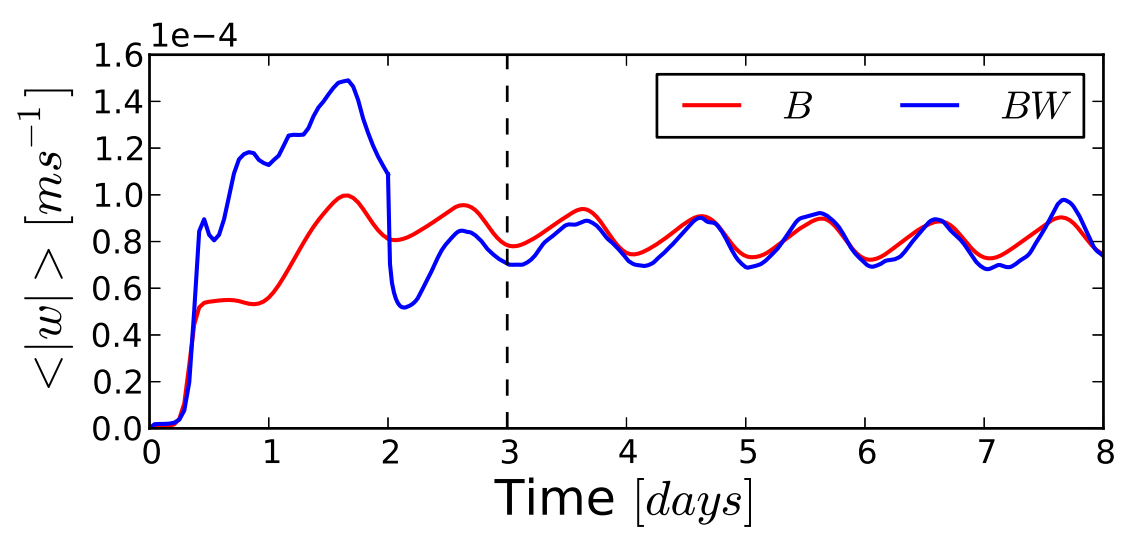

(b)

Figure 6: Time evolutions of (a) domain-averaged horizontal speed magnitude $\left[\mathrm{ms}^{-1}\right]$ and (b) vertical velocity magnitude $\left[\mathrm{m} \mathrm{s}^{-1}\right]$ for the entire integration time for both Exps. $B$ (red) and $B W$ (blue). The dashed lines mark the spin-up period.

\section{Material Transport}

In this section, transport characteristics in Exps. $B$ and $B W$ are investigated using Lagrangian dispersion and scale-dependent diffusivity from 2D and 3D particles. A 3D passive tracer is also released in the simulation since tracers provide a time-integrated view of transport processes, thereby becoming a complementary tool to 3D particles.

\subsection{Passive scalar transport}

First consider what happens to a surface concentration field under the action of a 2D compressible surface velocity field. Consider the concentration (density) of a conservative 
tracer at the surface, $C_{\rho}\left(\mathbf{x}_{h}, t\right)$ (where $\mathbf{x}_{h}=(x, y)$ ), which is transported by a $2 \mathrm{D}$ surface velocity field $\mathbf{u}_{h}\left(\mathbf{x}_{h}, t\right)$. Neglecting diffusive effects for simplicity, the evolution of $C_{\rho}$ is described by the advection equation,

$$
\frac{\partial C_{\rho}}{\partial t}+\nabla \cdot\left(\mathbf{u}_{h} C_{\rho}\right)=0 .
$$

Since the velocity field is not necessarily solenoidal, this becomes

$$
\frac{\partial C_{\rho}}{\partial t}+\mathbf{u}_{h} \cdot \nabla C_{\rho}=-\left(\nabla \cdot \mathbf{u}_{h}\right) C_{\rho} .
$$

The divergence of the vector field acts as a multiplicative forcing on the concentration field and the linear PDE is simply

$$
\frac{\partial C_{\rho}}{\partial t}+\mathbf{u}_{h} \cdot \nabla C_{\rho}=-\left(\nabla \cdot \mathbf{u}_{h}\right) C_{\rho}=f\left(\mathbf{x}_{h}, t\right) C_{\rho} .
$$

For uniform initial conditions and $f\left(\mathbf{x}_{h}, t\right)=0$, Eq. (12) has the unique solution of $C_{\rho}\left(\mathbf{x}_{h}, t\right)=C_{0}$. In fact, the only means of creating scalar gradients from an initially uniform scalar field is via the velocity divergence. This can be confirmed by using an initially uniform distribution for the scalar density. For area preserving flows, $\nabla \cdot \mathbf{u}_{h}=$ 0, initially uniform scalar density fields remain uniform. However, if there are spatial gradients of scalar density, then these gradients may be amplified by solenoidal velocity fields, namely by typical Lagrangian chaos. Taking the gradient of Eq. (12) yields:

$$
\frac{\partial \nabla C_{\rho}}{\partial t}+\left(\mathbf{u}_{h} \cdot \nabla\right) \nabla C_{\rho}=-\left(\left[\nabla \mathbf{u}_{h}\right]^{T}+\left(\nabla \cdot \mathbf{u}_{h}\right)\right) \nabla C_{\rho}-C_{\rho} \nabla\left(\nabla \cdot \mathbf{u}_{h}\right) .
$$

Eq. (13) shows that scalar gradients (indicative of clustering of surface material) can only be directly produced from initially uniform scalar fields by the velocity divergence. In fact, the production of scalar gradients requires that the gradient of the velocity divergence be non-zero.

Consider a uniform scalar field; Eq. (12) shows that $C_{\rho}\left(\mathbf{x}_{h}, t\right)$ will grow (decay) exponentially in regions of convergence (divergence). Thus, very rapidly, the initially 
uniform $C_{\rho}$ field will develop spatial gradients. Eq. (13) shows that these gradients will be advected by the velocity field and amplified by three distinct mechanisms: (1) production by stretching (2) production by divergence (3) production by gradient of the divergence. Some of these concepts have been demonstrated in idealized flows using passive particles by Schumacher and Eckhardt (2002), but we specifically explore these in the context of oceanic mixed layer dynamics, and we use a passive tracer instead.

In Exp. $B$, plumes were well organized at the surface and show regular structures of few hundred meters width. These structures were separated by convergence zones of cold temperature fronts mating the boundaries of convective plumes. These structures remain relatively coherent throughout the simulated period. A passive tracer was released after 72 hours over the first $3 m$ near the surface with a uniform concentration of $C=1$ in order to explore whether the divergence field has any impact on the subsequent distribution of the tracer. The tracer rapidly evolves along the upwelling (low concentrations) and downwelling (high concentrations) zones in both Exps. $B$ (Figures 7a, 7b) and $B W$ (Figures 8a, 8b).

In order to quantify this visual similarity, the time evolution of the correlation between the tracer concentration and horizontal divergence fields was computed from

$$
\operatorname{corr}\left(C, \nabla \cdot \mathbf{u}_{h}\right)=\sum_{i=1}^{N_{x}} \sum_{j=1}^{N_{y}} \frac{\left(C^{i j}-\langle C\rangle\right) \cdot\left(\nabla \cdot \mathbf{u}_{h}^{i j}-\left\langle\nabla \cdot \mathbf{u}_{h}\right\rangle\right)}{\operatorname{std}(C) \operatorname{std}\left(\nabla \cdot \mathbf{u}_{h}\right)}
$$

where $\langle C\rangle$ and $\left\langle\nabla \cdot \mathbf{u}_{h}\right\rangle$ were respectively the spatially-averaged tracer concentration and horizontal divergence averaged over the release depth from 1 to $3 \mathrm{~m}$,

$$
\langle C\rangle=\frac{1}{N_{x} N_{y} 3} \sum_{i, j, k=1}^{N_{x}, N_{y}, 3} C^{i j k} ; \quad\left\langle\nabla \cdot \mathbf{u}_{h}\right\rangle=\frac{1}{N_{x} N_{y} 3} \sum_{i, j, k=1}^{N_{x}, N_{y}, 3} \nabla \cdot \mathbf{u}_{h}^{i j k}
$$

and $\operatorname{std}(C)$ and $\operatorname{std}\left(\nabla \cdot \mathbf{u}_{h}\right)$ were the corresponding standard deviations. 


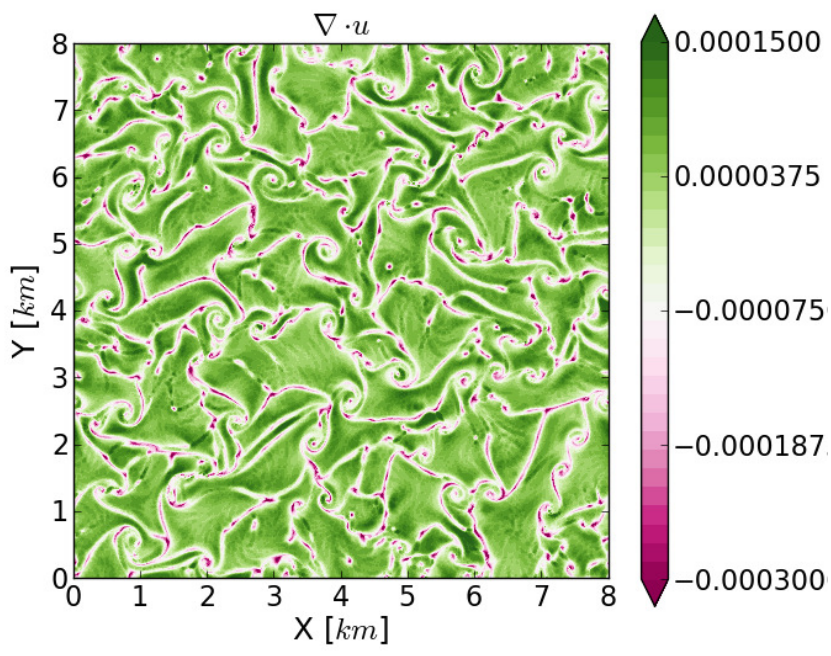

(a)

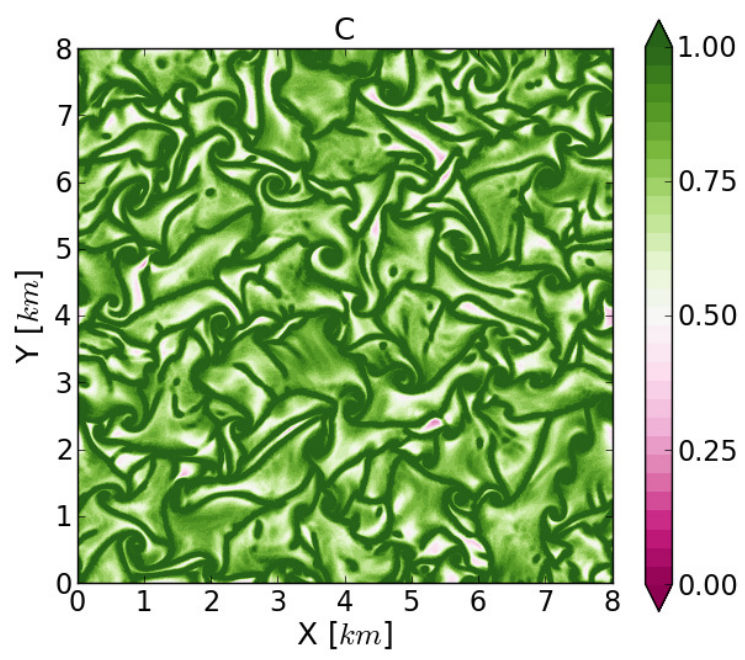

(b)

Figure 7: (a) Divergence $\left[\mathrm{s}^{-1}\right]$ of the horizontal velocity field averaged from 1 to $3 \mathrm{~m}$ depth and (b) passive tracer concentration averaged between 1 and $3 \mathrm{~m}, 1.5$ hours after the release in Exp. $B$.

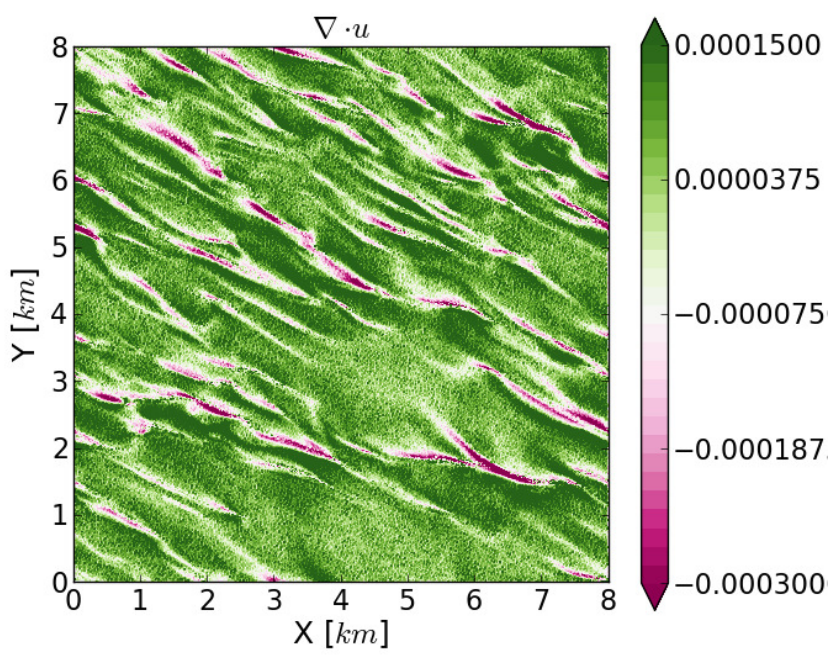

(a)

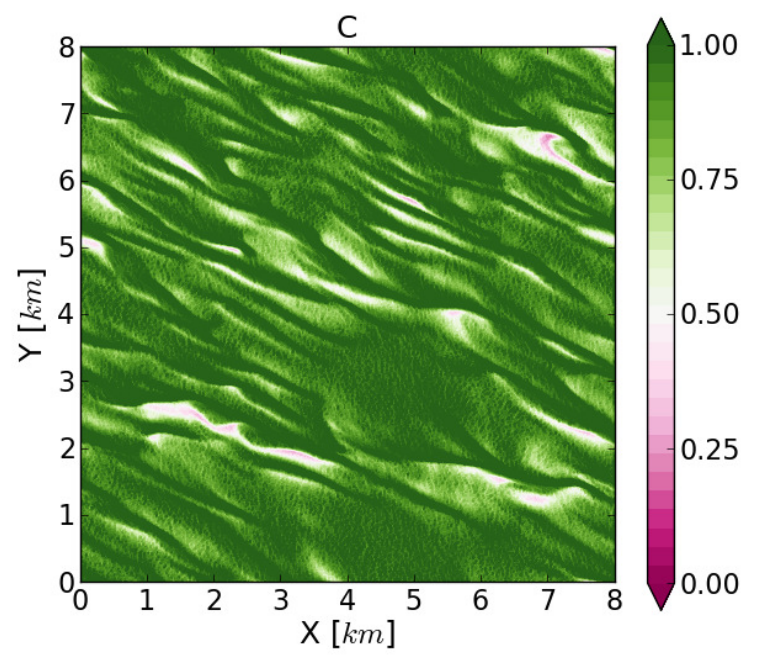

(b)

Figure 8: (a) Divergence $\left[\mathrm{s}^{-1}\right]$ of the horizontal velocity field averaged from 1 to $3 \mathrm{~m}$ depth and (b) passive scalar concentration averaged between 1 and $3 \mathrm{~m}, 1.2$ hours after the release in Exp. $B W$. 


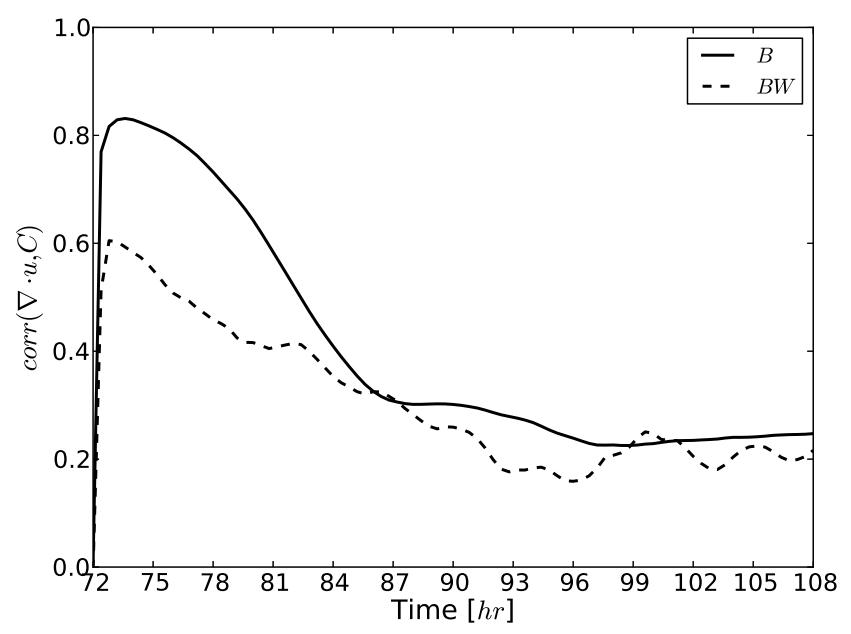

(a)

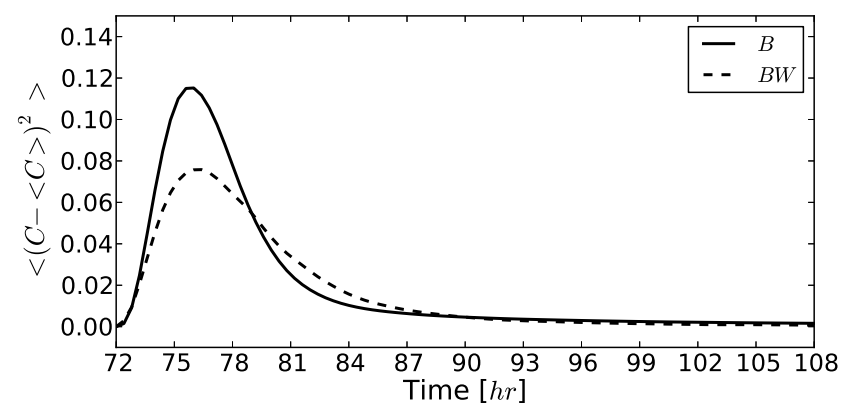

(b)

Figure 9: (a) Time dependence of the spatial correlation between the horizontal velocity divergence and tracer concentration for Exp. $B$ (solid) and Exp. $B W$ (dashed). (b) Time dependence of tracer concentration variance for Exp. $B$ (solid) and Exp. $B W$ (dashed).

Figure 9a shows that the horizontal divergence and tracer concentration fields were highly correlated with the highest correlation 1 to 3 hours after the tracer release into fully-developed fields for both cases. Similar plots are obtained if sections are taken near the surface (e.g. at $2 m$ ) instead of averaging over a few $m$ thick slab.

The loss of correlation that follows is essentially due to two factors: the rearrangement of the tracer patch due to stirring and mixing (which would happen also in the presence of $2 \mathrm{D}$ advection alone), and the loss of tracer from the upper ocean due to vertical motions. Tracer concentration and horizontal divergence will have the highest correlation at the earliest times and decay monotonically afterward. Correlation decay is also due to the vertical advection of tracer out of the upper ocean. Vertical advection is the largest at the convergence zones and so is the sequestration of tracer. Both these effects contribute 
to the reduction of correlation with time.

The tracer variance $\left\langle(C-\langle C\rangle)^{2}\right\rangle$ is shown in Figure 9b. The larger variance corresponding to Exp. $B$ supports the view that the surface tracer concentration was driven mainly by the horizontal divergence, while in Exp. $B W$ the horizontal advection was responsible for the weaker correlation with $\nabla \cdot \mathbf{u}_{h}$.

From the results of passive tracer releases with horizontally-uniform initial concentration, it is clear that the horizontal divergence by convection has a major influence on the distribution of surface material in the modeled OBL flows. This is a fundamentally different transport mechanism than stretching induced non-divergent coherent structures. Horizontal divergence/convergence results in the generation of scalar gradients, or clustering of surface material. Our results suggest that clustering can be generated within a matter of a few hours in oceanic mixed layers. In the real ocean, these features will subsequently be subject to stretching by submesoscale and/or mesoscale features that act on longer time scales. The resulting tracer patterns are of great importance for phytoplankton growth and interest in practical applications such as oil spills, because this inhomogeneity can influence response efforts and effectiveness of the resources deployed.

\subsection{Lagrangian transport}

In order to study horizontal dispersion in our simulations, particles were released after 72 hours of spin-up and advected offline using a fourth-order Runga-Kutta scheme in 2D (constant z-level) as well as in 3D. The justification for this approach is that while near-surface drifters were commonly employed in the ocean for decades (Davis, 1983), these were not fully Lagrangian in that they do not follow the motion of an infinitesimal neutrally-buoyant water parcel in a 3D velocity field. Because of the prominence of 3D motion in oceanic mixed layers (D'Asaro et al., 2002, 2011), it is important to investigate whether there is a difference between $2 \mathrm{D}$ and $3 \mathrm{D}$ sampling. Since surface waves were not included in our computations, the dynamics of the surface sublayer influenced by the wave motion is necessarily excluded from consideration.

In advecting particles, velocities were updated every $1440 \mathrm{~s}$. Particles were seeded in box of $5 \mathrm{~km}$ by $5 \mathrm{~km}$ in the middle of the domain every $10 \mathrm{~m}$ in both horizontal directions. 
2D releases were conducted at three selected depths of $5 \mathrm{~m}, 10 \mathrm{~m}, 15 \mathrm{~m}$, which were in the general range typical depths used in oceanic drogued drifters (Lumpkin and Pazos, 2007). A total of 750,000 particles were advected in each flow field.

In Exp. $B, 2 \mathrm{D}$ particles (Figure 10a) behave in a manner consistent with tracer releases and cluster together in the form of filaments and small eddies, under the influence of convergence regions. No significant difference is visible between $5 \mathrm{~m}$ and $15 \mathrm{~m}$ releases, indicating that the effect of the convergence regions in aggregating fixed-depth particles prevails at depth. Such filaments and streaks are of great interest for the behavior of $2 \mathrm{D}$ drifters in the field, as well as trapping of buoyant pollutants that remain close to the ocean's surface, such as oil or buoyant phytoplankton. In comparison, 3D particles show a more homogeneous distribution in the depth-averaged sense (Figure 10b), again lacking a significant visual difference between releases conducted from different depths. Interestingly, there is a striking similarity between the overall extent of particle dispersion from $2 \mathrm{D}$ and $3 \mathrm{D}$ releases. In other words, the outer bounds of dispersion are similar, while the interior patterns were significantly different, with 2D releases being characterized by patterns of clustering leading to substantial deviations from the mean pattern. 3D particles are free to move vertically and were advected inside convective plumes, and so be exposed to all scales of motion. This explains why the bulk dispersion is similar, but more small scale mixing is evident in the 3D particle simulations.

In Exp. $B W$, the addition of wind introduces significant depth dependence. For 2D releases, the near-surface pattern still shows clustering consistent with tracer results (Figure 10c). This effect penetrates through the wind-influenced layer, indicating that clustering is mainly driven by convective plumes. There is also significant vertical shear, propelling surface particles along the wind at much faster speed then in Exp. $B$ and implying that coherent structures are tilted in the vertical.

Wind forcing results in faster surface speed and therefore a faster spreading of the particle patch, and ultimately an increase in relative dispersion. A sense of the magnitude of the relative dispersion can be obtained from Figure 10, where particles are shown to cover a similar area after only 14 hours for Exp. $B W$, and in six days for Exp. $B$. 
This shows the importance of vertical shear dispersion on material transport. Qualitatively similar patterns were visible from 3D particles releases (Figure 10d), while, again, clustering is less pronounced with 3D sampling.

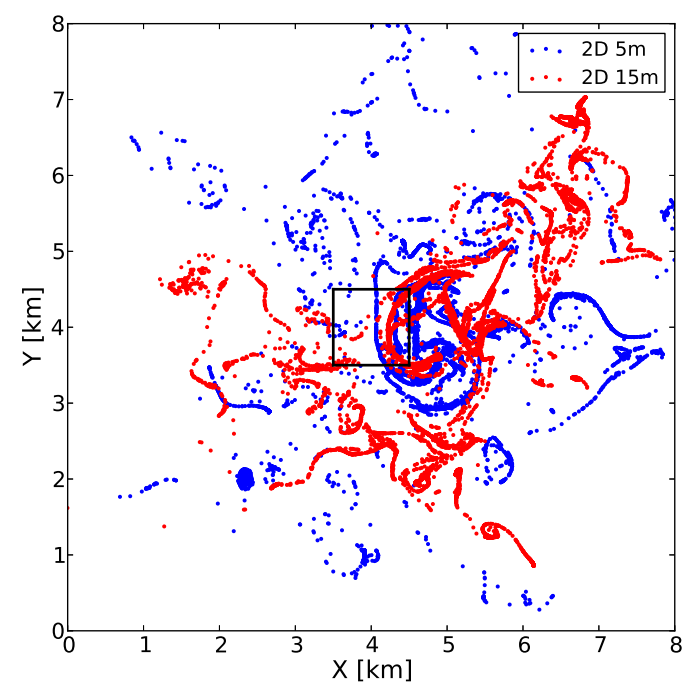

(a)

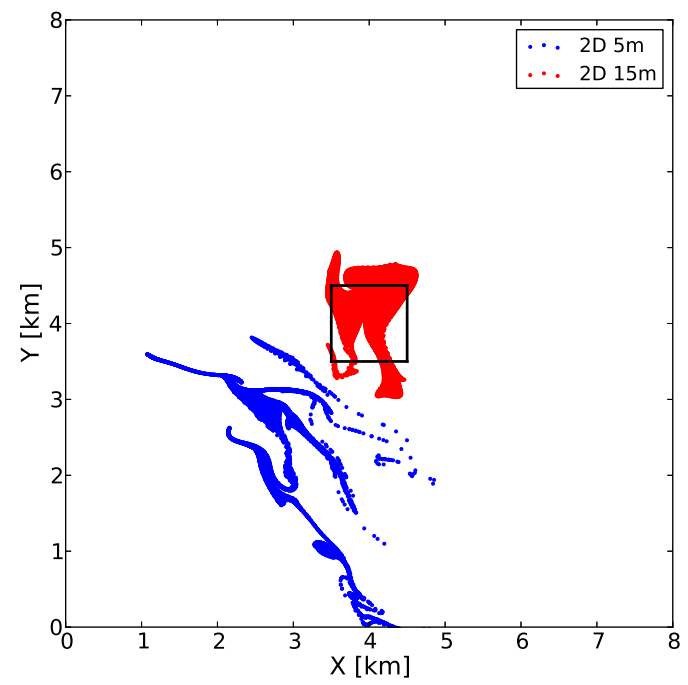

(c)

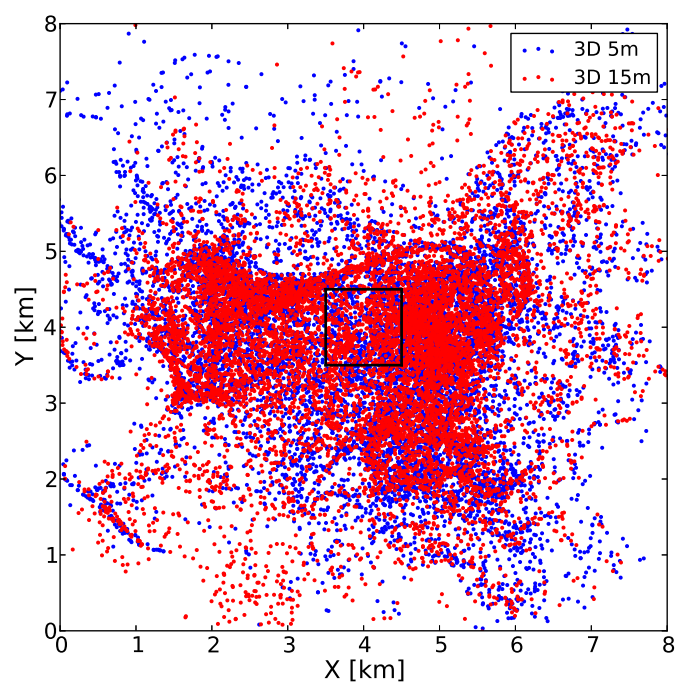

(b)

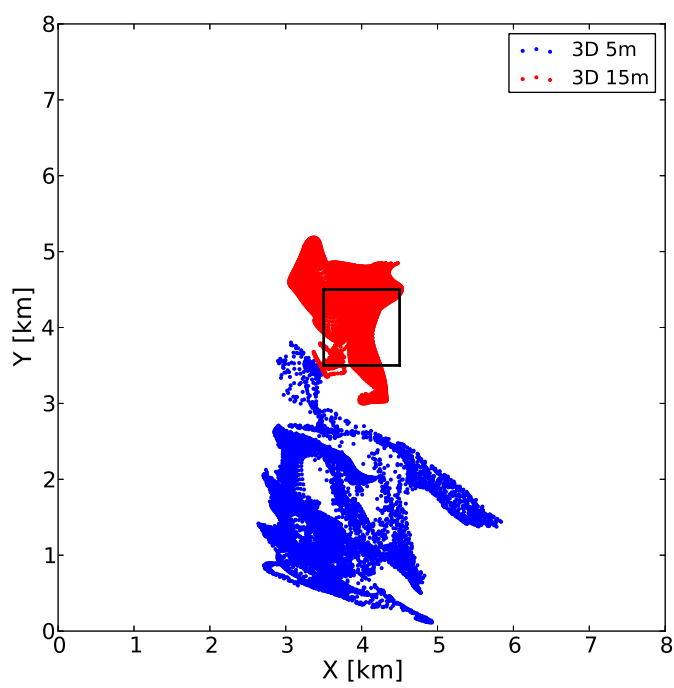

(d)

Figure 10: Horizontal location of a subset of particles released in a $1 \mathrm{~km}$ by $1 \mathrm{~km}$ box in the center of the domain in Exp. $B$ (a) using 2D advection, and (b) using 3D advection of particles released at $5 \mathrm{~m}$ (blue) and $15 \mathrm{~m}$ (red) depth after 144 hours of particle advection. Same for Exp. $B W$ in the case of (c) for 2D and (d) 3D particles after 14 hours of advection. 


\subsubsection{Horizontal relative dispersion}

Relative dispersion $\sigma_{D}^{2}(t)$, a metric for horizontal dispersion, is computed from

$$
\sigma_{D}^{2}(t)=\left\langle\left(\mathbf{r}_{1}(t)-\mathbf{r}_{2}(t)\right)^{2}\right\rangle
$$

where $\mathbf{r}$ is the particle horizontal position vector, and subscripts refer to particle pairs. Spreading is denoted non-local when it is dominated by features at scales larger than particle pair separation scale (Bennett, 1984). In the non-local dispersion regime, $\sigma_{D}^{2} \sim$ $\exp (\lambda t)$, where $\lambda$ is the Lyapunov exponent. When particles are sufficiently separated, $\sigma_{D}^{2}$ transitions to a local regime, where dispersion is driven by processes with the same scale as pair separation. This regime is typically characterized by the Richardson law, $\sigma_{D}^{2} \sim t^{3}$. When the scale of separation is much larger than the scale of the eddies, the diffusive regime, $\sigma_{D}^{2} \sim t$ can be attained. Sometimes, also a ballistic regime emerges, $\sigma_{D}^{2} \sim t^{2}$, where particle dispersion is dominated by horizontal shear (Iudicone et al., 2002). We refer the reader to Poje et al. (2010) and Özgökmen et al. (2012) for a recent discussion on the emergence of various dispersion regimes in the ocean for the purpose of brevity here.

Given that relative dispersion can show a super-diffusive character with such different growth rates, it has been a topic of investigation both in classical fluid mechanics and physical oceanography. Of particular interest is the Richardson's regime, which is observed in 2D turbulence (Babiano et al., 1990) as well as 3D turbulence (Boffetta and Sokolov, 2002) in classical fluid dynamics, thereby being the most general regime of all. Oceanic flows are driven by a large number of processes (as reviewed in Section 1), and it is a natural question to ask whether and over which scales Richardson's law would remain valid.

Richardson regime has been observed for mesoscales using floats (deep measurements) by LaCasce and Bower (2000); Ollitrault et al. (2005) in the North Atlantic, using 15 to $30 \mathrm{~m}$ drogued drifters in the Gulf of Mexico byLaCasce and Ohlmann (2003), in the nordic seas by Koszalka et al. (2009) and in the Ligurian Sea by Schroeder et al. (2011). 
There have been indications that the Richardson scaling extended into the submesoscale regime, most notably in studies by Lumpkin and Elipot (2010) in the North Atlantic, Schroeder et al. (2012) in the Ligurian Sea, and by Berti et al. (2011) in the Brazil Current. Modeling studies (Poje et al., 2010; Özgökmen et al., 2012; Haza et al., 2014) have demonstrated that the primary challenge in pinning down the statistical regime has been that the number of drifter pairs were either too low, or that the positioning accuracy needed for submesoscale dispersion was hard to attain in oceanic measurements. These obstacles have been overcome recently; using 300 drifters with a highly accurate positioning system and a high-frequency data stream, results consistent with the Richardson law were conclusively obtained in the northern Gulf of Mexico (Poje et al., 2014).

The next frontier is to identify what types of scaling laws can be expected for OBL flows modeled here, namely those subject to weak winds, and in the absence of waves, submesoscale fronts and mesoscale strain. A particular consideration is that the measurement of relative dispersion with adequate statistical accuracy is likely to be limited to the use of surface drifters, since the use of hundreds of Lagrangian floats (D'Asaro et al., 2002) is likely to be prohibitively expensive for the foreseeable future.

In Exp. $B$ (Figure 11) particles were released after the spin-up period (72 hours) and initially show an exponential regime because particle pair separation distances $(10 \mathrm{~m})$ were much smaller than the scale of the convection cells $(\mathcal{O}(100 m))$. Transition to a well-defined Richardson regime starts after 6 hours for $5 \mathrm{~m}$ releases and after 12 hours for $15 \mathrm{~m}$ releases. The Richardson scaling persists throughout the remainder of the analysis period, as also highlighted by the normalized $\left(\sigma_{D}^{2} t^{-3}\right)$ plot in the inset of Figure 11a. Sampling using 3D particles, initialized at a depth of $5 \mathrm{~m}$ (Figure 11b) shows very similar results to those from $2 \mathrm{D}$ particles. 


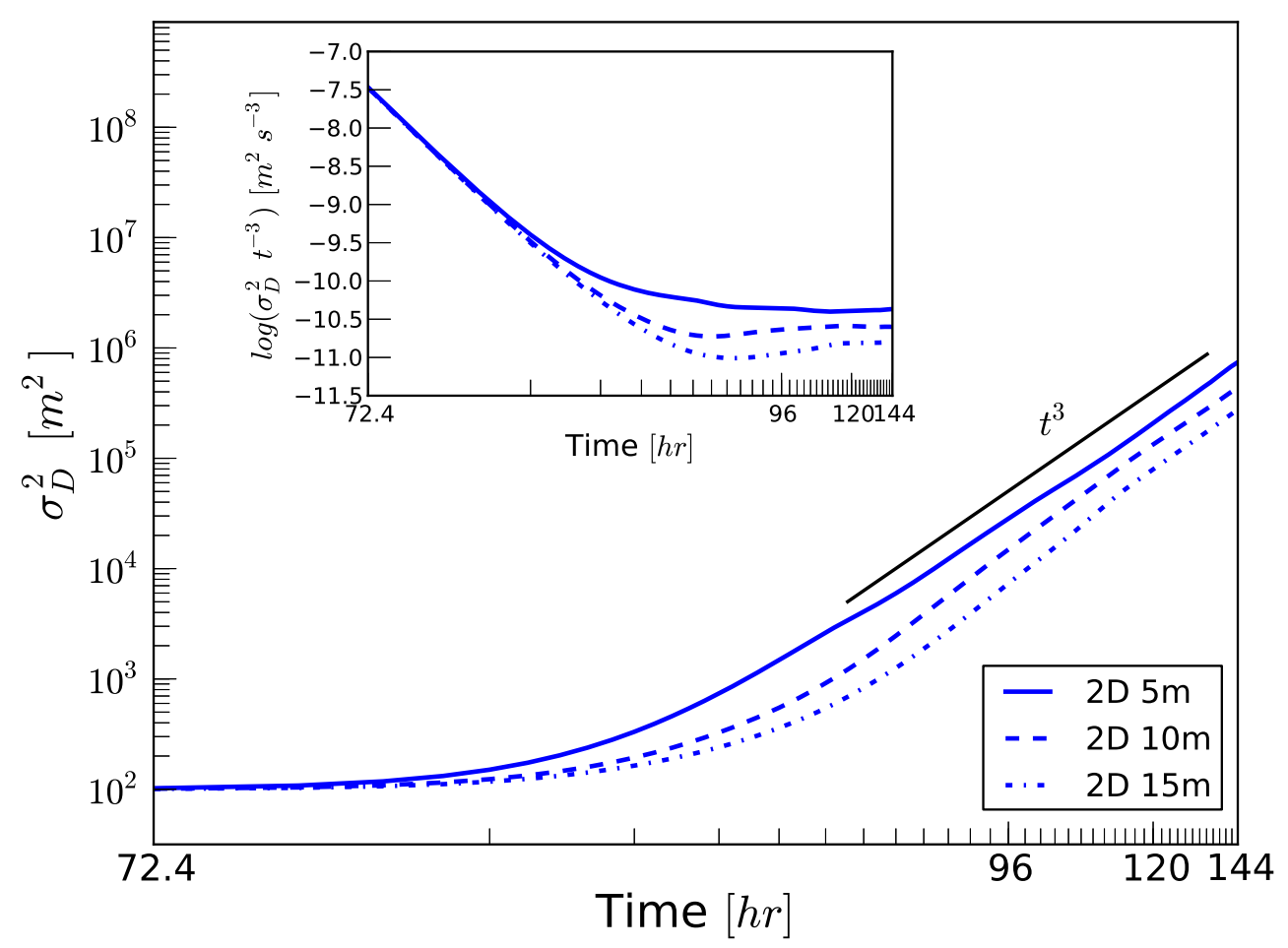

(a)

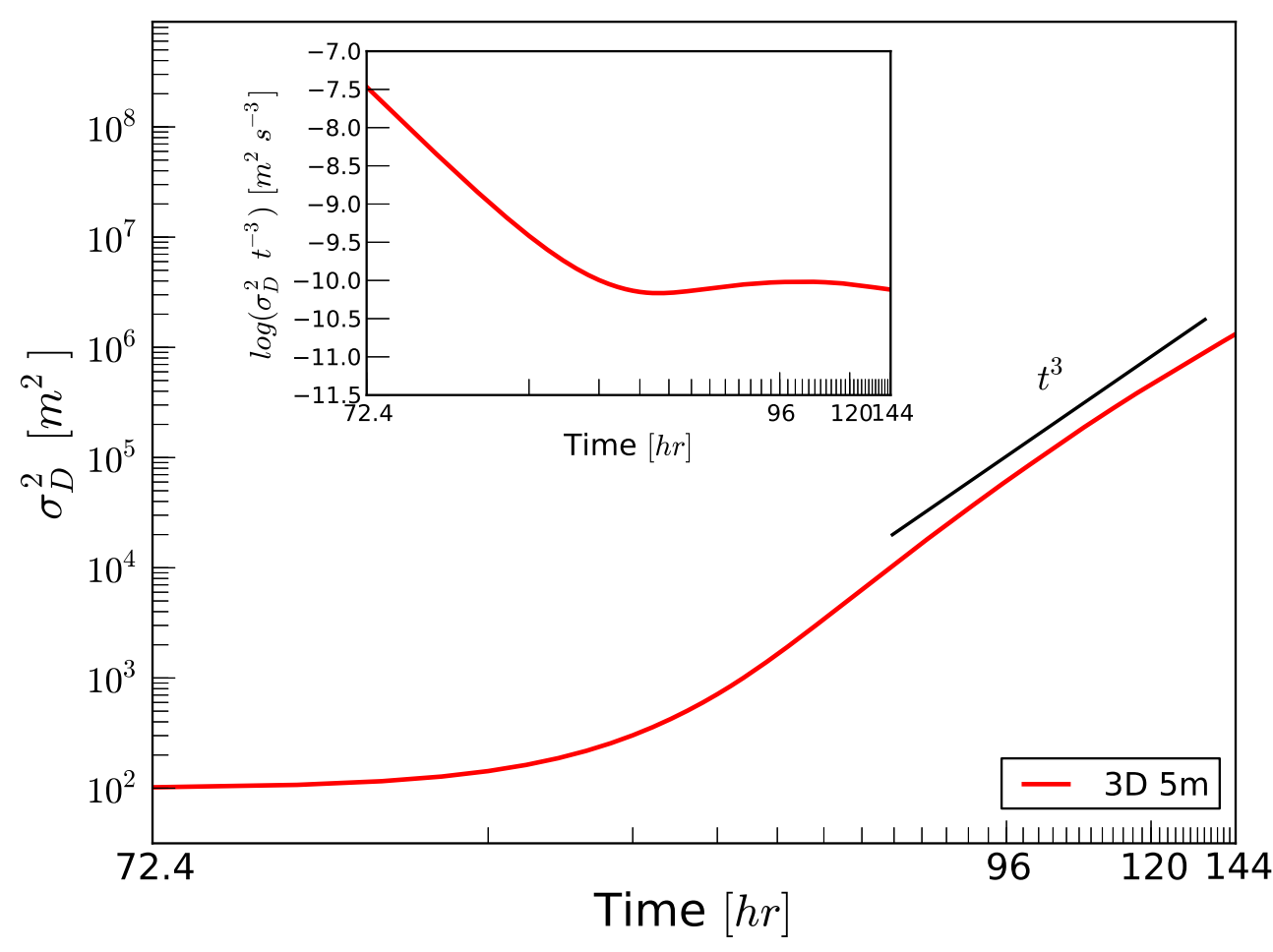

(b)

Figure 11: Relative dispersion $\sigma_{D}^{2}(t)$ for (a) 2D particles released at $5 \mathrm{~m}$ (solid), $10 \mathrm{~m}$ (dashed), $15 \mathrm{~m}$ (dashed-dotted) and (b) 3D particles in Exp. $B$. The slope $t^{3}$ shows the Richardson regime for reference. The insets show relative dispersion normalized by the Richardson regime. 


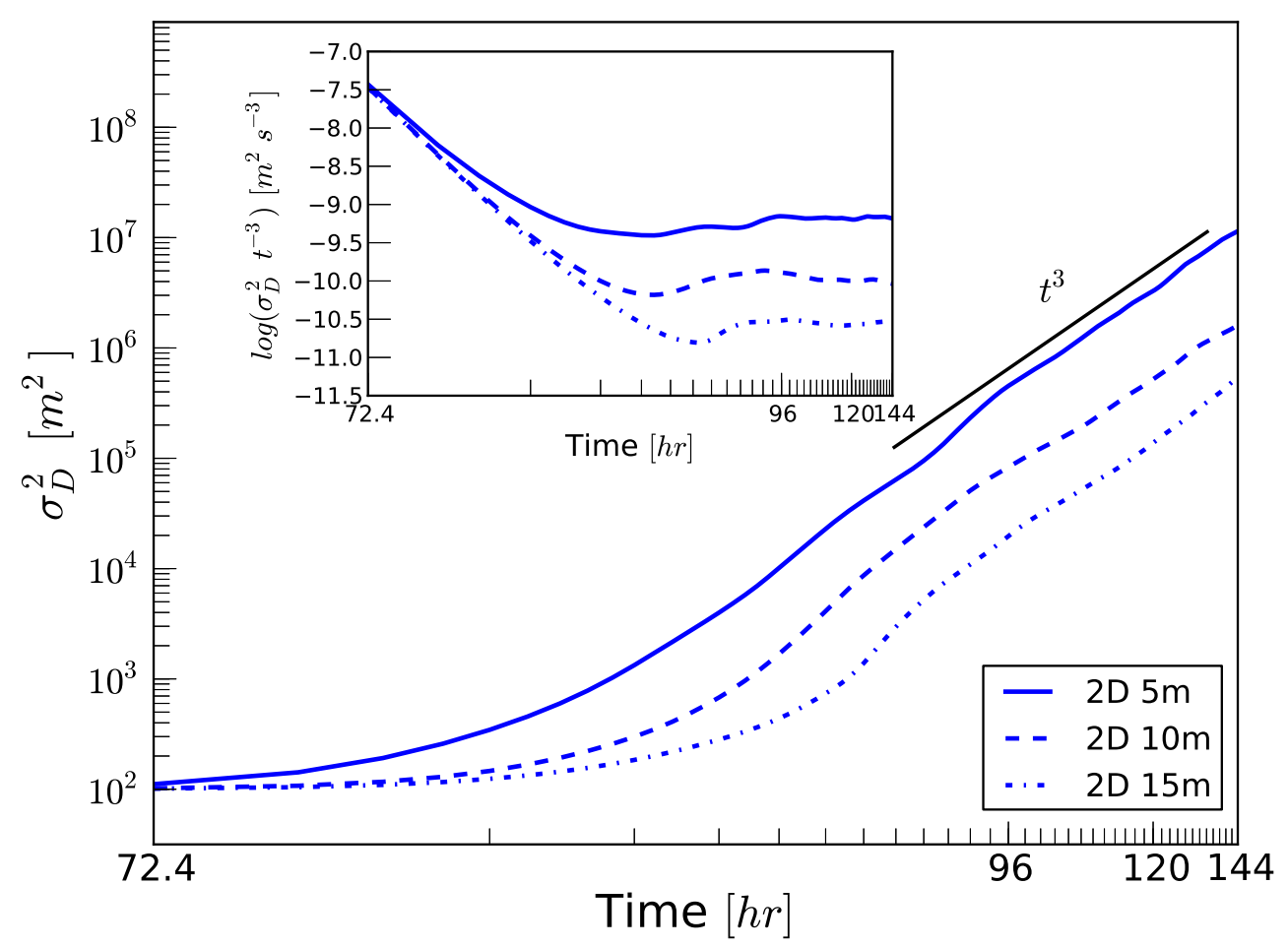

(a)

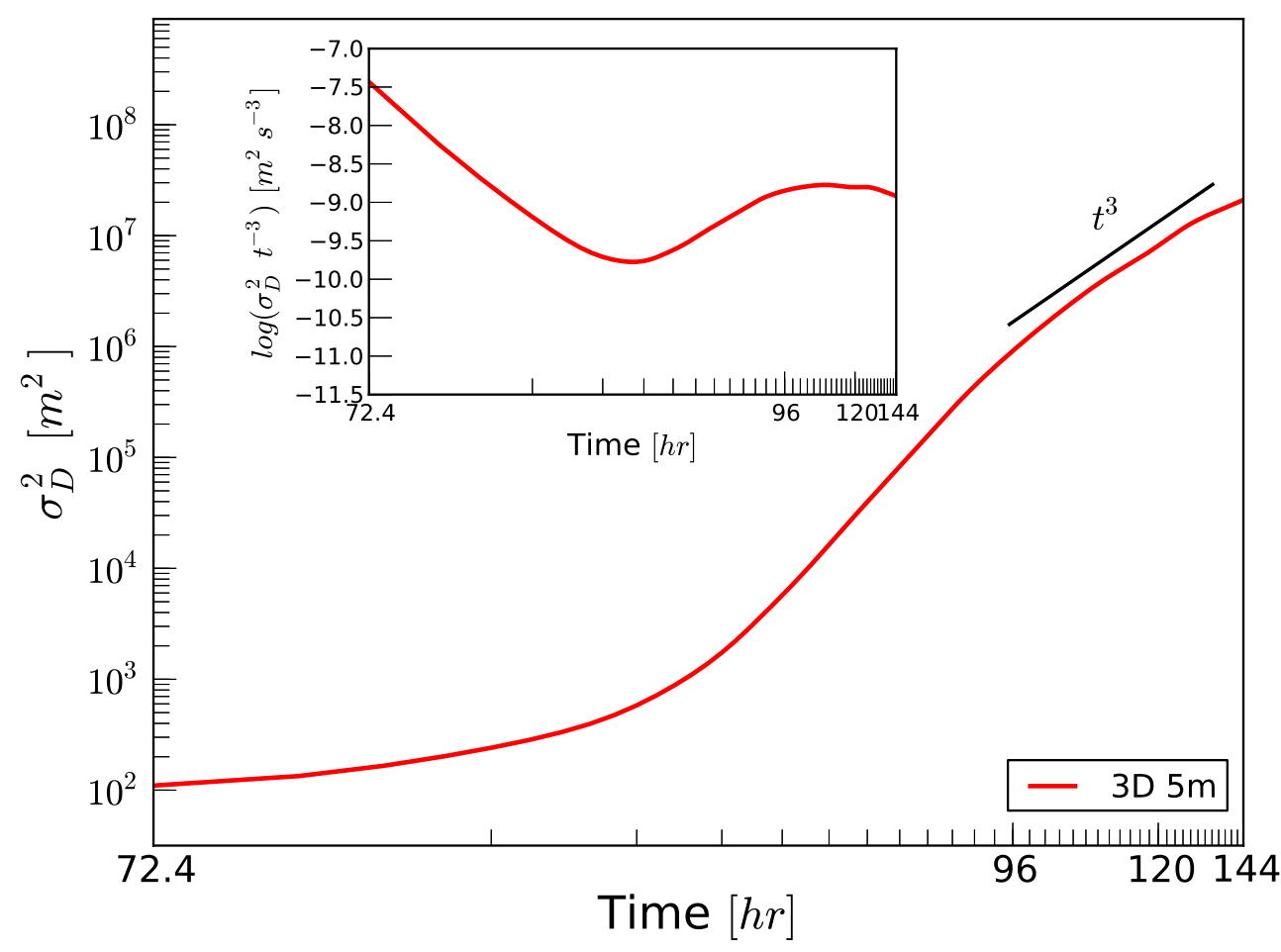

(b)

Figure 12: Relative dispersion $\sigma_{D}^{2}(t)$ for (a) 2D particles released at $5 \mathrm{~m}$ (solid), $10 \mathrm{~m}$ (dashed), $15 \mathrm{~m}$ (dashed-dotted) and (b) 3D particles in Exp. $B W$. The slope $t^{3}$ shows the Richardson regime for reference. The insets show relative dispersion normalized by the Richardson regime. 
In comparison, Exp. $B W$ (Figure 12) shows the following differences. 2D particles near the surface make a faster transition to Richardson scaling after 4 hours, for particle releases at $5 \mathrm{~m}$ depth, because the wind created anisotropic features with a smaller dynamical scale. 2D sampling had a more pronounced depth dependence (with deeper releases showing a delayed transition to Richardson's regime) in Exp. $B W$. In addition, the amplitude of relative dispersion was approximately an order of magnitude larger in Exp. $B W$ than in Exp. B. Furthermore, the transition to Richardson scaling emerged after a full 24 hours of the release of 3D particles in Exp. $B W$.

Richardson regime is realized in theory when the kinetic energy dissipation rate is constant, namely $D^{2}(t)=C \epsilon t^{3}$ (Ott and Mann, 2000; Boffetta and Sokolov, 2002), while in our simulations, as well as in the oceans, $\epsilon$ can vary by several orders of magnitude with depth, and this could lead to deviations from the Richardson regime. Since 2D particles move at a constant depth, a faster agreement is achieved with the Richardson regime. On the other hand, 3D particles travel through depth associated with different $\epsilon$-levels, and this could be the reason for delayed Richardson regime, or significant deviations from this regime early on.

\subsubsection{Scale-dependent horizontal diffusivities}

In his seminal work, Richardson (1926) pioneered the concept of scale-dependent diffusivity based on the notion that turbulence associated with different scales and/or processes consists of eddies of different sizes $(\ell)$ and speeds $(U)$. A small tracer patch encounters all these characteristic scales of motion while spreading, thereby being subject to different diffusivities ( $\sim \ell$, as per Prandtl's (1925) mixing length argument). Okubo (1970) compiled results from a series of measurements in lakes and coastal oceans, and estimated the scale-dependent diffusivity $k_{D}$ from

$$
k_{D}=\frac{\sigma_{D}^{2}}{4 t}
$$

According to Richardson (1926), the slope of $k_{D}$ with respect to the length scale $\ell$ should follow $k_{D} \sim \ell^{4 / 3}$ (so-called 4/3rd law), which is fundamentally consistent with the 3D 
turbulence theory by Kolmogorov (1941). This is remarkable in that both formulations rely on the assumption of constant turbulent kinetic energy dissipation rate $\epsilon$ throughout the kinetic energy wavenumber spectrum. For a fully-developed Richardson regime, scaling analysis yields $\sigma_{D}^{2} \sim \epsilon t^{3}$ (Boffetta and Sokolov, 2002). The diagrams compiled by Okubo $(1970,1971)$ showed that the Richardson regime was observed for individual experiments, but when the full collection of observations was considered, Okubo concluded that $k_{D} \approx 0.0103 \ell^{1.15}$ was a better fit, where $\ell=3 \sigma_{D}$ and the factor 3 is because three standard deviations from the mean are needed to cover $99 \%$ of the particle's patch under the assumption of a Gaussian distribution. The exponent 1.15 is somewhat less steep than the Richardson's regime.

The possible emergence of the Richardson law was the central focus of a large surface dispersion experiment conducted in the northern Gulf of Mexico recently. These results, discussed in Poje et al. (2014), extended Okubo's scatter plot to larger length scales and a perfect agreement with the Richardson scaling was found for diffusivity. The difference in the scale-dependence coefficient of 1.15 vs 1.33 is quite small, nevertheless, this issue can still benefit from further investigation, in particular about how it depends on 2D vs 3D sampling.

The scale-dependent diffusivity for Exp. $B$ (Figure 13a and 13b) shows overall smaller values (by up to an order of magnitude) for both 2D and 3D particles respect to Okubo's results. 3D sampling shows a slope which is closer to the Richardson power law than 2D sampling. 


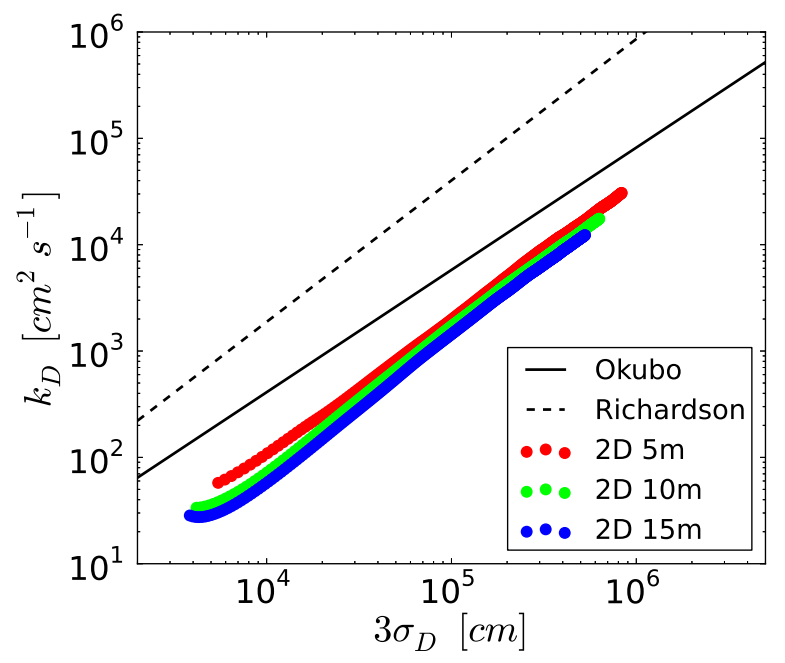

(a)

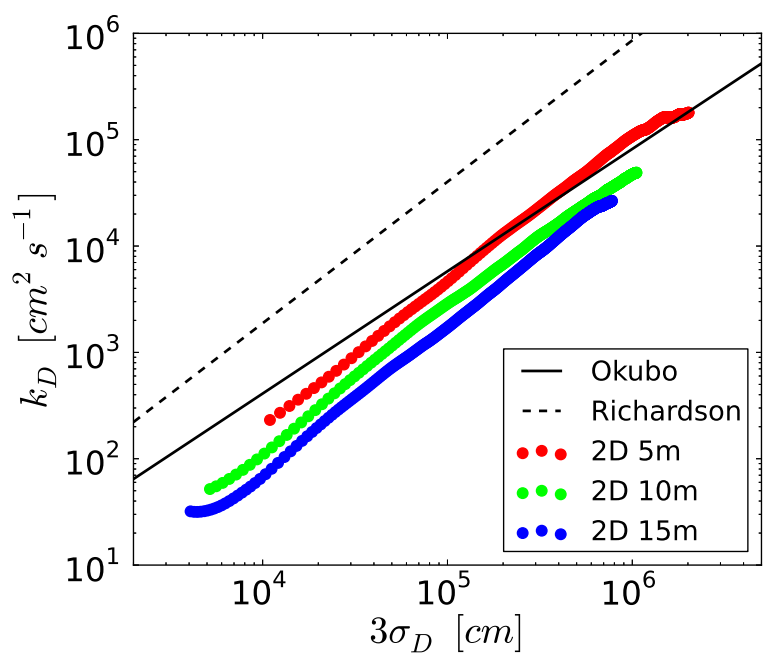

(c)

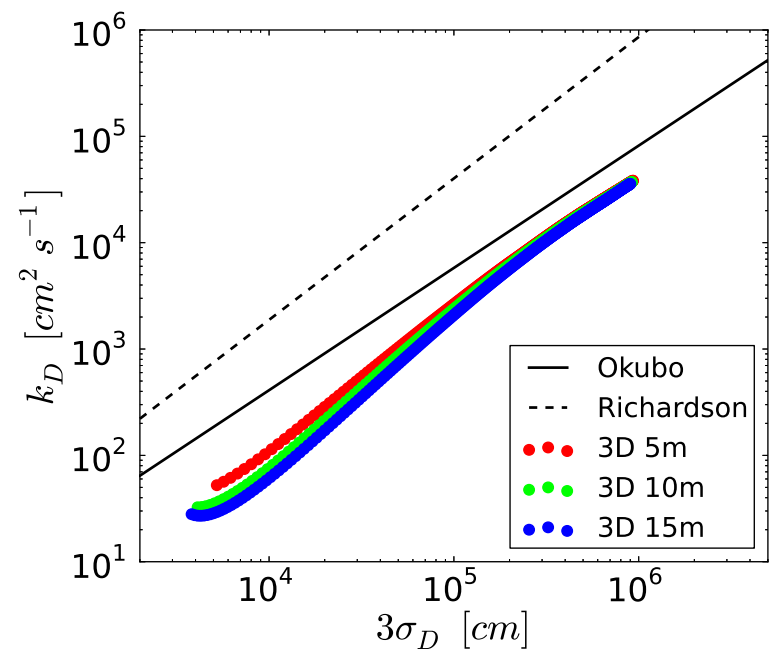

(b)

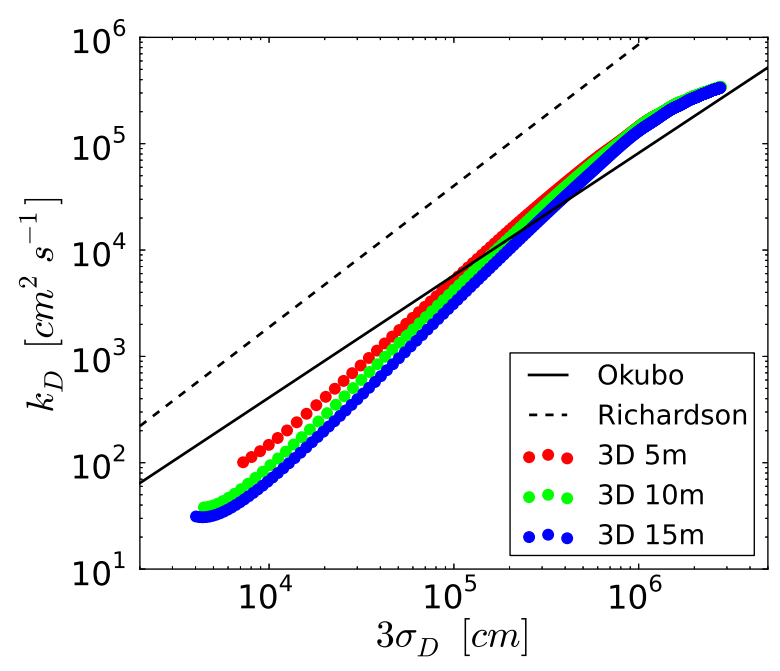

(d)

Figure 13: Scale-dependent relative diffusivity $k_{D}(\ell)$ for Exp. $B$ (upper panels (a), (b)) and Exp. $B W$ (lower panels, (c), (d)) using 2D sampling (left panels) and 3D sampling (right panels). Diffusivity is computed from particles released at $5 \mathrm{~m}$ (red), $10 \mathrm{~m}$ (green) and $15 \mathrm{~m}$ (blue) depths. Okubo's (1970) curve is plotted for reference in solid line. The dashed line marks Richardson's scaling of $k_{D} \sim \ell^{4 / 3}$ (amplitude for the dashed line is arbitrary).

When the wind is added (Figures 13c and 13d), a better agreement with Okubo (1970) is attained in terms of the amplitude of $k_{D}$. Vertical shear and overall larger horizontal velocities substantially contribute to diffusivity. Apparently, the horizontal dispersive effect of wind missing in Exp. $B$ is quite important to get results that are consistent with previous oceanic estimates for scale-dependent diffusivity. 
and given that $\nu_{i j}$ is defined as $\nu_{i j}=\left(\nu_{h}, \nu_{h}, \nu_{z}\right)$ we use the following expression for $\epsilon$,

$$
\epsilon=2 \nu_{h} \overline{\left(\frac{\partial u^{\prime}}{\partial x}\right)^{2}}+2 \nu_{h} \overline{\left(\frac{\partial v^{\prime}}{\partial y}\right)^{2}}+2 \nu_{z} \overline{\left(\frac{\partial w^{\prime}}{\partial z}\right)^{2}}
$$

531 where $u^{\prime}, v^{\prime}$ and $w^{\prime}$ are turbulent fluctuations, which are taken as anomalies with respect 532 similar to Okubo. On the other hand, 2D 15m depth particles have a slope similar to Richardson but an amplitude approximately half that of Okubo (1970). Finally, with 3D sampling of the flow field in Exp. $B W$, the amplitude of $k_{D}(\ell)$ is close to Okubo's measurements at all depths, while the scaling is consistent with the Richardson power law.

\subsubsection{Vertical dissipation, dispersion and diffusivity}

The daily cycle of a convective mixed layer has been extensively studied in lakes, oceans and numerical models (Imberger, 1985; Brainerd and Gregg, 1993a,b; D’Asaro et al., 2002; Nagai et al., 2005; Yeates et al., 2013). A quantity of general interest is the kinetic energy dissipation rate $\epsilon\left[W K^{-1}\right]$.

Considering the full expression for $\epsilon$ (Hinze, 1959),

$$
\epsilon=\nu_{i j} \overline{\left(\frac{\partial u_{i}^{\prime}}{\partial x_{j}}+\frac{\partial u_{j}^{\prime}}{\partial x_{i}}\right) \frac{\partial u_{i}^{\prime}}{\partial x_{j}}},
$$
to the horizontal and temporal mean.

The 2D 5m depth particles have a slope similar to Richardson, but an amplitude 


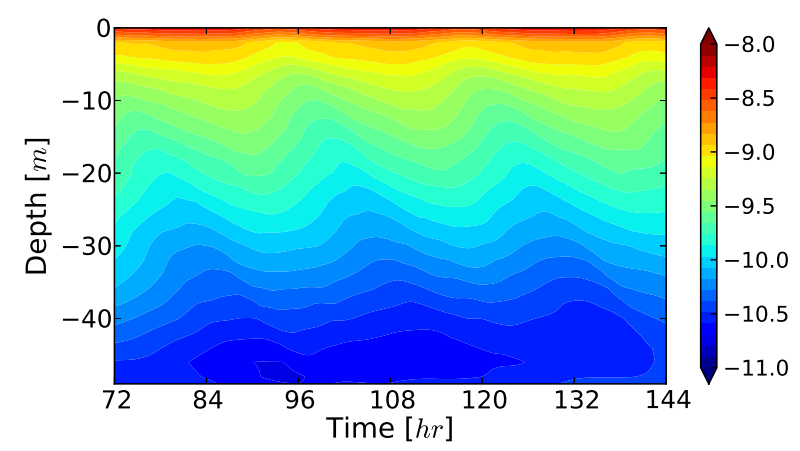

(a)

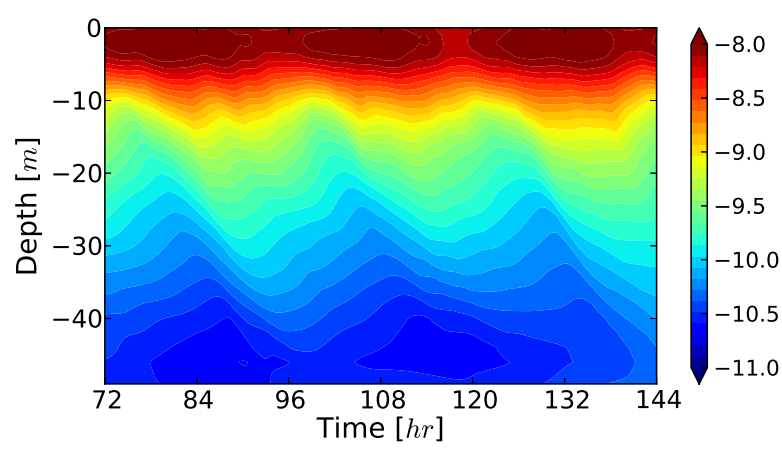

(b)

Figure 14: Temporal and vertical variability of the horizontally-averaged kinetic energy dissipation rate $\log (\epsilon)\left[W K^{-1}\right]$ for (a) Exp. $B$ and (b) Exp. $B W$ over three days after the spin-up.

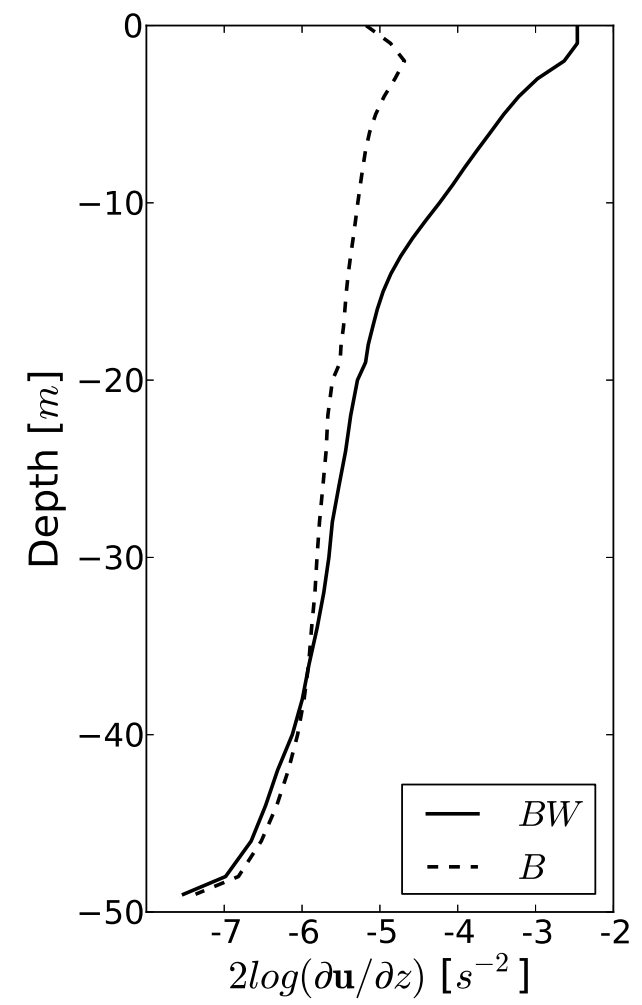

Figure 15: Depth dependence of horizontally-averaged vertical shear after 72 hours for Exps. $B$ (dashed) and $B W$ (solid).

The daily cycle of the kinetic energy dissipation rate in the modeled flow fields is similar to what was observed in the real ocean under similar conditions (Brainerd and Gregg, 1993a) and presents a relatively stable cycle in time (Figure 14).

Given that we have only one process (rotating convective cells and their wind-sheared counterpart), we cannot capture oceanic dissipation rates from micro-structure profilers, 
in which the higher dissipation rates could be driven either by injection of energy by local processes, such as waves and small-scale wind events, or energy cascade by instabilities in the submesoscale range.

Kinetic energy dissipation rate for Exp. $B W$ and Exp. $B$ shows qualitatively the same time dependency with deepening of the mixing layer at night and restratification during the day. The region of highest dissipation is much thicker in Exp. $B W$ reaching down to $15 \mathrm{~m}$. In Figure 15 we compute the horizontally averaged vertical shear $\left\langle\log \left((d u / d z)^{2}+(d v / d z)^{2}\right)\right\rangle$. Values are up to two orders of magnitude larger in Exp. $B W$ than Exp. $B$ in the upper $15 \mathrm{~m}$ of the domain, consistent with the difference in the kinetic energy dissipation rate.

Vertical eddy diffusivity $K_{z}$ is used to quantify vertical dispersion in the mixed layer. Here, $K_{z}$ is estimated from passive particle releases at different depths. In particular, $K_{z}$ is computed from (Babiano et al., 1990)

$$
K_{z}=\frac{1}{2} \frac{d \sigma_{D_{z}}^{2}(t)}{d t}
$$

where $\sigma_{D_{z}}^{2}(t)$ is vertical relative dispersion

$$
\sigma_{D_{z}}^{2}(t)=\left\langle\left(z_{1}(t)-z_{2}(t)\right)^{2}\right\rangle
$$

where $z$ is the particle depth, and subscripts refer to particle pairs. To compute vertical relative dispersion, particles are released in two layers $0.5 \mathrm{~m}$ apart (half the vertical mesh spacing) in the vertical and $100 \mathrm{~m}$ apart horizontally.

Vertical relative dispersion (Figure 16) is found to be consistent with Richardson scaling, $\sigma_{D z}^{2}(t) \sim t^{3}$. For Exp. $B$, Richardson's regime is observed for $80 \leq t \leq 120$ hours for particles released at $t=72$ hours, while in Exp. $B W$, the transition to Richardson regime starts faster at $t=74$ hours, due to the strong vertical shear and generation of smaller scale features by the anisotropy induced by wind. 


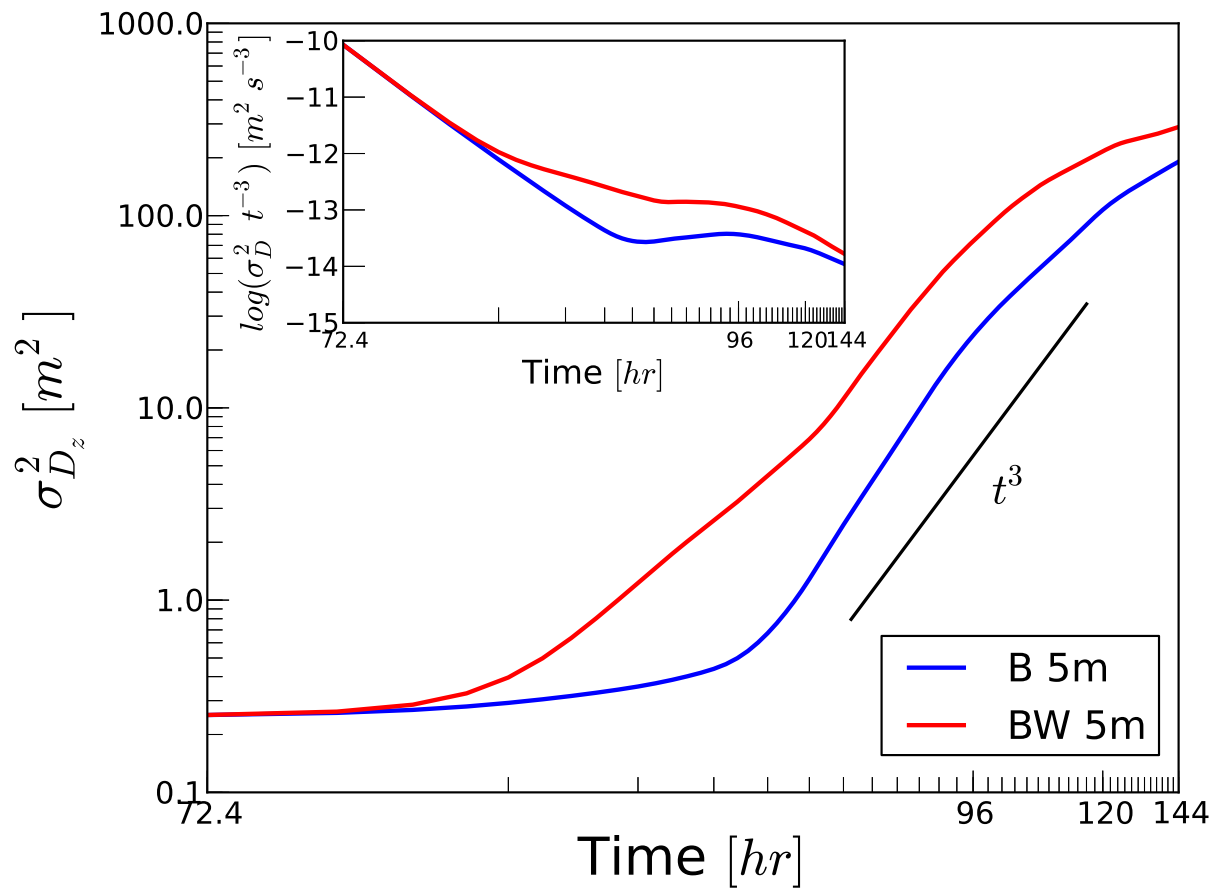

Figure 16: Relative vertical dispersion $\sigma_{D_{z}}^{2}(t)$ computed from 3D particle released at $5 \mathrm{~m}$ depth. The black line has slope $t^{3}$ characteristic of Richardson regime and the inset shows normalized dispersion $\sigma_{D}^{2}$. The thick marks along the time axis are 2 hours apart.

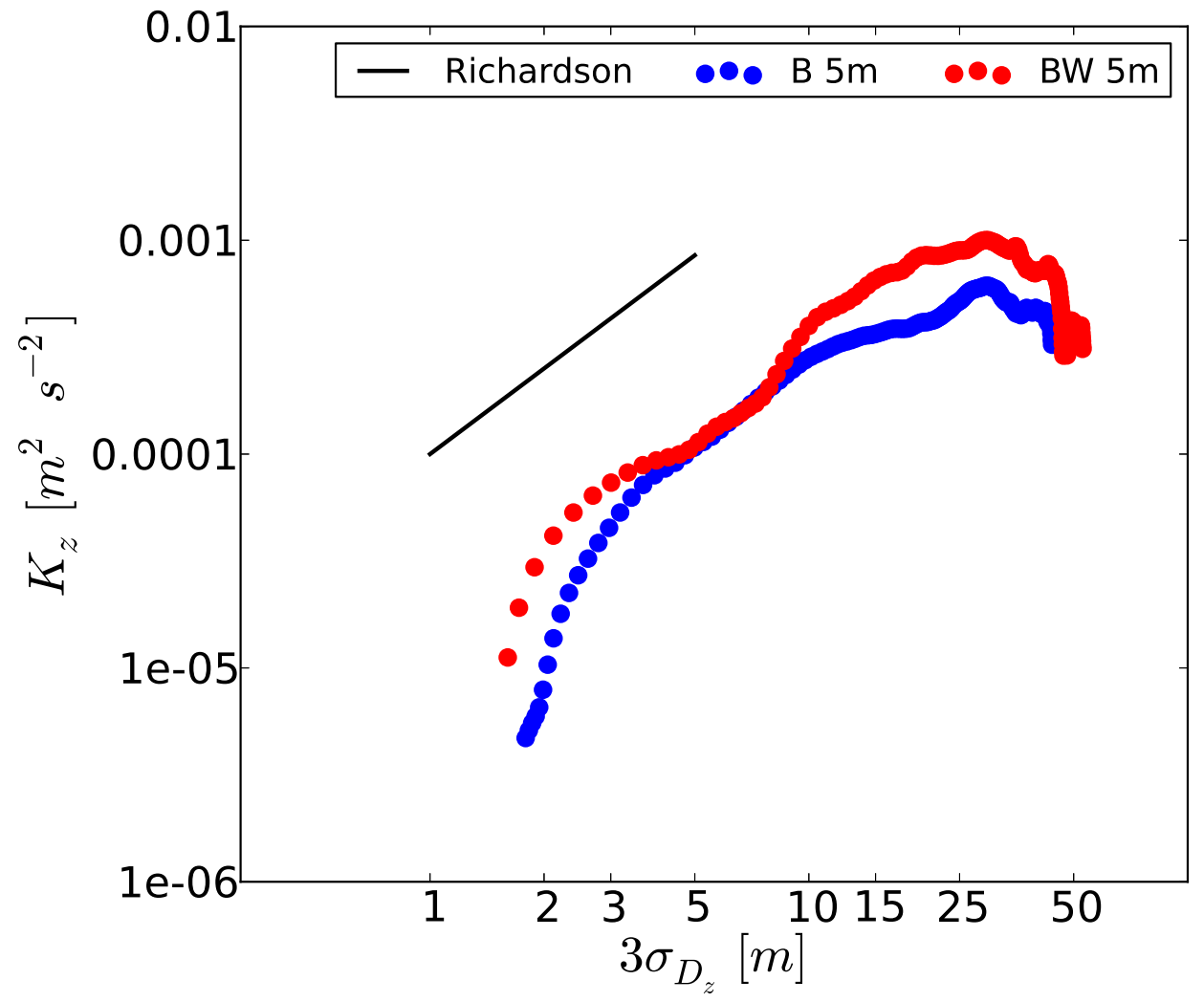

Figure 17: Relative vertical diffusivity $K_{z}$ versus length scale for particles released at $t=$ 72 hours in both experiments. The canonical Richardson slope $\ell_{z}^{4 / 3}$ is shown for comparison. 
In order to define the scale dependence of eddy diffusivity, we plot $K_{z}$ as a function of the length scale $\ell_{z}=3 \sigma_{D_{z}}$. Results are shown in Figure 17 for particles released at $t=72$ hours at $5 \mathrm{~m}$ depth in both simulations. Overall, we find that vertical diffusivity has a sharp cut off at the vertical mesh scale of several meters, and then changes by an order of magnitude from $\approx 10^{-4} \mathrm{~m}^{2} \mathrm{~s}^{-1}$ (excluding the sharp drop at the subgrid scale) to a maximum of $\approx 10^{-3} \mathrm{~m}^{2} \mathrm{~s}^{-1}$ at the depth scale of the mixed layer. The values of vertical eddy diffusivity for the wind-driven case are higher. For length scales between several times the mesh size and the total depth of the domain, diffusivity scales with $K_{z} \sim \ell_{z}^{4 / 3}$, which is again consistent with the Richardson regime. Vertical eddy diffusivity plateaus at scales of about $\ell_{z} \sim 50 \mathrm{~m}$ which corresponds to the full vertical extent of the domain.

\section{Summary and conclusions}

Motivated by the importance of transport processes in the upper ocean mixed layer, most notably those involving biogeochemical particles, and buoyant pollutants such as oil, numerical simulations of forced mixed layer flows were conducted using a non-hydrostatic model. We focus on flows driven by low wind speeds of $\left|\boldsymbol{u}_{10}\right|=5 \mathrm{~ms}^{-1}$, because it is a common, thus important state, yet an under-investigated regime in the ocean.

We found that the horizontal flow divergence that is generated by convective cells near the surface controls particle motion in that it leads to the accumulation of surface material along convergence zones. Within hours after the release of a surface tracer, a high correlation was established with the horizontal divergence field. This correlation lasts about 12 hours, or the entire length of the cooling cycle, after which the tracer was fully homogenized through the mixed layer circulation. It should be noted however, that the modeled flows do not contain the larger scale strain fields that can be also exerted by submesoscale and/or mesoscale flows on near-surface tracers or particles. The factors determining the distribution of surface material in the ocean have important practical implications, bringing dynamical support to the adage "90\% of the oil in $10 \%$ of the area" (Oil in the Sea: Inputs Fates and Effects, 2003).

By sampling the flow fields with 2D and 3D passive particles, we observe a clear emer- 
gence of a Richardson regime in relative dispersion in both simulated cases. Sampling of the flow field by $2 \mathrm{D}$ and $3 \mathrm{D}$ particles did not result in a significant difference in Exp. $B$, but the depth dependence in dispersion was pronounced in Exp. $B W$, with surface 2D releases transitioning to the Richardson's regime faster due to smaller scale features created by stretching along the wind direction. In addition, horizontal relative dispersion in the wind-forced case was about an order of magnitude larger than in the buoyancy-forced case, showing the importance of wind forcing data for future observational experiments.

Values of scale-dependent diffusivity are similar to Okubo's results when the simulation was forced by both wind and buoyancy forcing. In the case of Exp. $B$, diffusivity was about one order of magnitude smaller than Okubo's values. For 2D particles, a good agreement in diffusivity was reached only for particles released close to the surface. This is consistent with the findings of Poje et al. (2014) from surface drifters at $1 \mathrm{~m}$ depth. When 3D sampling is used, the slope of the scale-dependent diffusivity steepens from Okubo's $\left(k_{D} \sim \ell^{1.15}\right)$ to Richardson's $\left(k_{D} \sim \ell^{4 / 3}\right)$ estimate, and all curves seem to collapse. This result implies a somewhat reduced diffusivity for surface-bound tracers, even though the differences were admittedly small. The absence of submesoscale motions in the simulations, due to the uniformity of the forcing, introduced a plateau in the growth of the dispersion coefficient at a horizontal scale given by the convective structures.

Investigations of the relative contributions of Langmuir turbulence and/or submesoscale restratification to OBL dispersion seem to be among those too pursue as future work.

\section{Acknowledgements}

We were grateful to the Office of Naval Research (grant \# N000141110087) for providing the support for Ph.D. student J.A. Mensa. Efforts of T.M. Özgökmen and A.C. Poje were funded by a grant from the BP/The Gulf of Mexico Research Initiative. The authors appreciate the support by the Center for Computational Science at the University of Miami. This manuscript forms the CWR 2675 publication. The authors thank three anonymous reviewers whose comments helped improve the manuscript. 


\section{References}

Babiano, A., Basdevant, C., Le Roy, P., Sadourny, R., 1990. Relative dispersion in twodimensional turbulence. Journal of Fluid Mechanics 214, 535-557.

Batchelor, G. K., 1952. The effect of homogeneous turbulence on material lines and surfaces. Proceedings of the Royal Society of London. 213 (1114), 349-366.

Belcher, S. E., Grant, A. L. M., Hanley, K. E., Fox-Kemper, B., Van Roeke, L., Sullivan, P. P., Large, W. G., Brown, A., Hines, A., Calvert, D., Rutgersson, A., Pettersson, H., Bidlot, J. R., Janssen, P. A. E. M., Polton, J. A., 2012. A global perspective on Langmuir turbulence in the ocean surface boundary layer. Geophysical Research Letters 39 (17), 1-9.

Bennett, A., 1984. Relative dispersion: local and nonlocal dynamics. Journal of Atmospheric Sciences 41, 1881-1886.

Berti, S., Santos, F. A. D., Lacorata, G., Vulpiani, A., 2011. Lagrangian drifter dispersion in the Southwestern Atlantic Ocean. Journal of Physical Oceanography 41 (1), 16591672.

Boccaletti, G., Ferrari, R., Fox-Kemper, B., 2007. Mixed layer instabilities and restratification. Journal of Physical Oceanography 37 (9), 2228-2250.

Bodenschatz, E., Werner, P., Guenter, A., 2000. Recent developments in Rayleigh-Bénard convection. Annual Review of Fluid Mechanics 32, 709-778.

Boffetta, G., Sokolov, I., 2002. Relative dispersion in fully developed turbulence: The Richardsons Law and intermittency corrections. Physical Review Letters 88 (9), 1-4.

Botelho, D., Imberger, J., Dallimore, C., Hodges, B. R., 2009. A hydrostatic/nonhydrostatic grid-switching strategy for computing high-frequency, high wave number motions embedded in geophysical flows. Environmental Modelling \& Software 24 (4), $473-488$. 
Brainerd, K., Gregg, M., 1993a. Diurnal restratification and turbulence in the oceanic surface mixed layer: 1. Observations. Journal of Geophysical Research: Oceans 98 (C12), $22645-22656$.

Brainerd, K., Gregg, M., 1993b. Diurnal restratification and turbulence in the oceanic surface mixed layer: 2. Modeling. Journal of Geophysical Research: Oceans 98 (C12), $22657-22664$

Brainerd, K., Gregg, M., 1995. Surface mixed and mixing layer depths. Deep Sea Research Part I: Oceanographic Research Papers 42 (95), 1521-1543.

Capet, X., McWilliams, J. C., Molemaker, M. J., Shchepetkin, A. F., 2008. Mesoscale to submesoscale transition in the California Current system. Part I: Flow structure, eddy flux, and observational tests. Journal of Physical Oceanography 38 (1), 29-43.

Chelton, D. B., Schlax, M. G., Samelson, R. M., de Szoeke, R. A., 2007. Global observations of large oceanic eddies. Geophysical Research Letters 34, 1-5.

Cotter, C. J., Ham, D. A., Pain, C. C., 2009. A mixed discontinuous/continuous finite element pair for shallow-water ocean modelling. Ocean Modelling 26 (1-2), 86-90.

Craik, A. D. D., Leibovich, S., 1976. A rational model for Langmuir circulations. Journal of Fluid Mechanics 73 (3), 401-426.

Crone, T., Tolstoy, M., 2010. Magnitude of the 2010 Gulf of Mexico oil leak. Science 330, 634.

D’Asaro, E. A., 2001. Turbulent Vertical Kinetic Energy in the Ocean Mixed Layer. Journal of Physical Oceanography 31 (12), 3530-3537.

D'Asaro, E. A., 2014. Turbulence in the upper-ocean mixed layer. Annual Review of Marine Science 6, 101-115.

D'Asaro, E. A., Farmer, D., 1996. A Lagrangian float. Journal of Atmospheric and Oceanic Technology 13, 1230-1246. 
D’Asaro, E. A., Lee, C., Rainville, L., Harcourt, R., Thomas, L., 2011. Enhanced turbulence and energy dissipation at ocean fronts. Science 332 (6027), 318-322.

D'Asaro, E. A., Thomson, J., Shcherbina, A. Y., Harcourt, R. R., Cronin, M. F., Hemer, M. A., Fox-Kemper, B., 2014. Quantifying upper ocean turbulence driven by surface waves. Geophysical Research Letters 41 (1), 102-107.

D'Asaro, E. A., Winters, K., Lien, R., 2002. Lagrangian analysis of a convective mixed layer. Journal of Geophysical Research 107 (C5), 1-17.

Davis, R., Ohman, M., Rudnick, D., 2008. Glider surveillance of physics and biology in the southern California Current system. Limnology \& Oceanography 53, 2151-2168.

Davis, R. E., 1983. Oceanic property transport, Lagrangian particle statistics, and their prediction. Journal of Marine Research 41, 163-194.

Fox-Kemper, B., Ferrari, R., Hallberg, R., 2008. Parameterization of mixed layer eddies. Part I: Theory and diagnosis. Journal of Physical Oceanography 38 (6), 1145-1165.

Gregg, M. C., 1989. Scaling turbulent dissipation in the thermocline. Journal of Geophysical Research 94 (C7), 9686-9698.

Grooms, I., Julien, K., Weiss, J. B., Knobloch, E., 2010. Model of convective Taylor columns in rotating Rayleigh-Bénard convection. Physical Review Letters 104 (224501), $1-4$.

Hamlington, P. E., Van Roekel, L. P., Fox-Kemper, B., Julien, K., Chini, G. P., 2014. Langmuirsubmesoscale interactions: Descriptive analysis of multiscale frontal spindown simulations. Journal of Physical Oceanography 44 (9), 2249-2272.

Harcourt, R. R., 2013. A second-moment closure model of Langmuir turbulence. Journal of Physical Oceanography 43 (4), 673-697.

Harcourt, R. R., D'Asaro, E. A., 2008. Large-Eddy Simulation of Langmuir Turbulence in Pure Wind Seas. Journal of Physical Oceanography 38 (7), 1542-1562. 
Haza, A. C., Özgökmen, T. M., Griffa, A., Poje, A. C., Lelong, M.-P., 2014. How does drifter position uncertainty affect Ocean dispersion estimates? Journal of Atmospheric and Oceanic Technology 31 (12), 2809-2828.

Haza, A. C., Poje, A. C., Özgökmen, T. M., Martin, P., 2008. Relative dispersion from a high-resolution coastal model of the Adriatic Sea. Ocean Modelling 22 (1-2), 48-65.

Heitmann, S., Backhaus, J., 2005. Large-eddy simulations of convective shear flows. Deep Sea Research Part II: Topical Studies in Oceanography 52 (9-10), 1156-1180.

Hinze, J. O., 1959. Turbulence: an introduction to its mechanism and theory. McGrawHill series in mechanical engineering. McGraw-Hill.

Hunkins, K., 1966. Ekman drift currents in the Arctic Ocean. Deep Sea Research and Oceanographic Abstracts 13, 607-620.

Imberger, J., 1985. The diurnal mixed layer. Limnology and Oceanography 30 (4), 737770.

Iudicone, D., Lacorata, G., Rupolo, V., Santoleri, R., Vulpiani, A., 2002. Sensitivity of numerical tracer trajectories to uncertainties in OGCM velocity fields. Ocean Modelling $4,313-325$.

James, I., 2002. Modelling pollution dispersion, the ecosystem and water quality in coastal waters: a review. Environmental Modelling \& Software 17 (4), 363-385.

Jerlov, N. G., 1968. Optical Oceanography. Elsevier Oceanography Series. Elsevier Science.

Jernelöv, A., Lindén, O., 1981. IXTOC I: A case study of the world's largest oil spill. Ambio 10 (6), 299-306.

Jones, H., Marshall, J., 1993. Convection with rotation in a neutral ocean: A study of open-ocean deep convection. Journal of Physical Oceanography 23, 1009-1039. 
Klein, P., Lapeyre, G., 2009. The oceanic vertical pump induced by mesoscale and submesoscale turbulence. Annual Review of Marine Science 1 (1), 351-375.

Kolmogorov, A., 1941. Dissipation of energy in locally isotropic turbulence. Proceedings: Mathematical and Physical Sciences 434 (1890), 15-17.

Koszalka, I., LaCasce, J. H., Orvik, K. A., 2009. Relative dispersion in the Nordic Seas. Journal of Marine Research 67 (4), 411-433.

Kramer, S., Cotter, C., Pain, C., 2010. Solving the Poisson equation on small aspect ratio domains using unstructured meshes. Ocean Modelling 35 (3), 253-263.

Kraus, E. B., Turner, J. S., 1967. A one-dimensional model of the seasonal thermocline II. Tellus 1, 98-106.

Kukulka, T., Plueddemann, A. J., Trowbridge, J. H., Sullivan, P. P., 2010. Rapid Mixed Layer Deepening by the Combination of Langmuir and Shear Instabilities: A Case Study. Journal of Physical Oceanography 40 (11), 2381-2400.

LaCasce, J., 2008. Statistics from Lagrangian observations. Progress In Oceanography 77 (1), 1-29.

LaCasce, J., Bower, A., 2000. Relative dispersion in the subsurface North Atlantic. Journal of Marine Research 58, 863-894.

LaCasce, J. H., Ohlmann, C., 2003. Relative dispersion at the surface of the Gulf of Mexico. Journal of Marine Research 61 (3), 285-312.

Langmuir, I., 1938. Surface motion of water induced by wind. Science 87 (2250), 119-123.

Large, W., Yeager, S., 2004. Diurnal to decadal global forcing for ocean and sea-ice models: The data sets and flux climatologies. NCAR Technical Note NCAR/TN-460+STR.

Leibovich, S., Tandon, A., 1993. Three-dimensional Langmuir circulation instability in a stratified layer. 
Lévy, M., Iovino, D., Resplandy, L., Klein, P., Madec, G., Tréguier, A.-M., Masson, S., Takahashi, K., 2011. Large-scale impacts of submesoscale dynamics on phytoplankton: Local and remote effects. Ocean Modelling 44, 77-93.

Lévy, M., Klein, P., Treguier, A.-M., 2001. Impact of sub-mesoscale physics on production and subduction of phytoplankton in an oligotrophic regime. Journal of Marine Research $59(4), 535-565$.

Lumpkin, R., Elipot, S., 2010. Surface drifter pair spreading in the North Atlantic. Journal of Geophysical Research 115 (C12), 1-20.

Lumpkin, R., Pazos, M., 2007. Measuring surface currents with Surface Velocity Program drifters: the instrument, its data, and some recent results. In: Lagrangian Analysis and Prediction of Coastal and Ocean Dynamics. Cambridge University Press, pp. 39-67.

Machado, D. A., Imberger, J., 2013. Modeling the impact of natural and anthropogenic nutrient sources on phytoplankton dynamics in a shallow coastal domain, Western Australia. Environmental Fluid Mechanics 14, 87-111.

Mahadevan, A., D’Asaro, E., Lee, C., Perry, M. J., 2012. Eddy-driven stratification initiates North Atlantic spring phytoplankton blooms. Science 337 (6090), 54-58.

Marmorino, G. O., Smith, G. B., Toporkov, J. V., Sletten, M. A., Perkovic, D., Frasier, S. J., 2009. Airborne imagery of ocean mixed-layer convective patterns. Deep Sea Research Part I: Oceanographic Research Papers 56 (3), 435-441.

McGillicuddy, D. J., Anderson, L. A., Bates, N. R., Bibby, T., Buesseler, K. O., Carlson, C. A., Davis, C. S., Ewart, C., Falkowski, P. G., Goldthwait, S. A., Hansell, D. A., Jenkins, W. J., Johnson, R., Kosnyrev, V. K., Ledwell, J. R., Li, Q. P., Siegel, D. A., Steinberg, D. K., 2007. Eddy/wind interactions stimulate extraordinary mid-ocean plankton blooms. Science 316 (5827), 1021-1026.

McGillicuddy, D. J., Robinson, A. R., 1998. Influence of mesoscale eddies on new production in the Sargasso Sea. Nature 285 (1977), 263-266. 
McWilliams, J. C., 2008. Fluid dynamics at the margin of rotational control. Environmental Fluid Mechanics 8 (5-6), 441-449.

McWilliams, J. C., Sullivan, P. P., 2000. Vertical mixing by Langmuir circulations. Spill Science and Technology Bulletin 6 (3-4), 225-237.

McWilliams, J. C., Sullivan, P. P., Moeng, C.-H., 1997. Langmuir turbulence in the ocean. Journal of Fluid Mechanics 334, 1-30.

Mensa, J. A., Garraffo, Z., Griffa, A., Özgökmen, T. M., Haza, A., Veneziani, M., 2013. Seasonality of the submesoscale dynamics in the Gulf Stream region. Ocean Dynamics $63(8), 923-941$.

Moeng, C., Sullivan, P., 1994. A comparison of shear-and buoyancy-driven planetary boundary layer flows. Journal of the Atmospheric Sciences 51 (7), 999-1022.

Nagai, T., Yamazaki, H., Nagashima, H., Kantha, L., 2005. Field and numerical study of entrainment laws for surface mixed layer. Deep Sea Research Part II: Topical Studies in Oceanography 52 (9-10), 1109-1132.

Oil in the Sea: Inputs Fates, Effects, N. R. C., 2003. Oil in the Sea III: Inputs, Fates, and Effects. The National Academies Press.

Okubo, A., 1970. Horizontal dispersion of floatable particles in the vicinity of velocity singularities such as convergences. In: Deep Sea Research. Vol. 17. Elsevier, pp. 445454.

Okubo, A., 1971. Oceanic diffusion diagrams. Deep Sea Research 18, 789-802.

Ollitrault, M., Gabillet, C., De Verdière, A. C., 2005. Open ocean regimes of relative dispersion. Journal of Fluid Mechanics 533, 381-407.

Ott, S. r., Mann, J., 2000. An experimental investigation of the relative diffusion of particle pairs in three-dimensional turbulent flow. Journal of Fluid Mechanics 422, $207-223$. 
Özgökmen, T., Poje, A., Fischer, P., 2012. On multi-scale dispersion under the influence of surface mixed layer instabilities and deep flows. Ocean Modelling 56, 16-30.

Özgökmen, T., Poje, A., Fischer, P., Haza, A., 2011. Large eddy simulations of mixed layer instabilities and sampling strategies. Ocean Modelling 39, 311-331.

Özgökmen, T. M., Fischer, P. F., 2012. CFD application to oceanic mixed layer sampling with Lagrangian platforms. International Journal of Computational Fluid Dynamics $26(6-8), 1-12$.

Paulson, C., Simpson, J., 1977. Irradiance measurements in the upper ocean. Journal of Physical Oceanography 7, 952-956.

Piggott, M., Gorman, G., Pain, C., Allison, P., Candy, A., Martin, B., Wells, M., 2008. A new computational framework for multiscale ocean modelling based on adapting unstructured meshes. International Journal for Numerical Methods in Fluids 56, 10031015.

Poje, A. C., Haza, A. C., Özgökmen, T. M., Magaldi, M. G., Garraffo, Z. D., 2010. Resolution dependent relative dispersion statistics in a hierarchy of ocean models. Ocean Modelling 31 (1-2), 36-50.

Poje, A. C., Ozgökmen, T. M., Lipphardt, B. L., Haus, B. K., Ryan, E. H., Haza, A. C., Jacobs, G. A., Reniers, A. J. H. M., Olascoaga, M. J., Novelli, G., Griffa, A., Beron-Vera, F. J., Chen, S. S., Coelho, E., Hogan, P. J., Kirwan, A. D., Huntley, H. S., Mariano, A. J., 2014. Submesoscale dispersion in the vicinity of the Deepwater Horizon spill. Proceedings of the National Academy of Sciences of the United States of America $111(35), 12693-12698$.

Price, J. F., Weller, R. A., Pinkel, R., 1986. Diurnal cycling: Observations and models of the upper ocean response to diurnal heating, cooling, and wind mixing. Journal of Geophysical Research 91 (C7), 8411-8427.

Price, J. F., Weller, R. A., Schudlich, R. R., 1987. Wind-driven ocean currents and ekman transport. Science 238 (4833), 1534-1538. 
Reed, M., Johansen, O., Brandvik, P., Daling, P., Lewis, A., Fiocco, R., Mackay, D., Prentki, R., 1999. Oil spill modeling towards the close of the 20th century: Overview of the state of the art. Spill Science \& Technology Bulletin 5 (1), 3-16.

Richardson, L., 1926. Atmospheric diffusion shown on a distance-neighbour graph. Proceedings of the Royal Society of London. Series A. 110 (756), 709-737.

Rossby, H., 1969. A study of Bénard convection with and without rotation. Journal of Fluid Mechanics 36, 309-335.

Rossby, T., 2007. Evolution of Lagrangian methods in oceanography. In: Lagrangian Analysis and Prediction of Coastal and Ocean Dynamics. Cambridge University Press, pp. 1-38.

Sanford, T. B., Kelly, K. A., Farmer, D. M., 2011. Sensing the ocean. Physics Today $64(2), 24-28$.

Sasaki, H., Klein, P., Qiu, B., Sasai, Y., 2014. Impact of oceanic-scale interactions on the seasonal modulation of ocean dynamics by the atmosphere. Nature Communications $5,5636$.

Schroeder, K., Chiggiato, J., Haza, A., Griffa, A., Özgökmen, T. M., Zanasca, P., Molcard, A., Borghini, M., Poulain, P. M., Gerin, R., Zambianchi, E., Falco, P., Trees, C., 2012. Targeted Lagrangian sampling of submesoscale dispersion at a coastal frontal zone. Geophysical Research Letters 39 (11), 4-9.

Schroeder, K., Haza, A., Griffa, A., Özgökmen, T. M., Poulain, P., Gerin, R., Peggion, G., Rixen, M., 2011. Relative dispersion in the Liguro-Provençal basin: From submesoscale to mesoscale. Deep Sea Research Part I: Oceanographic Research Papers $58(3), 209-228$.

Schumacher, J., Eckhardt, B., 2002. Clustering dynamics of Lagrangian tracers in freesurface flows. Physical Review E 66 (017303), 1-4. 
Scotti, A., Mitran, S., 2008. An approximated method for the solution of elliptic problems in thin domains: Application to nonlinear internal waves. Ocean Modelling 25, 144-153.

Shcherbina, A. Y., D’Asaro, E. A., Lee, C. M., Klymak, J. M., Molemaker, M. J., McWilliams, J. C., 2013. Statistics of vertical vorticity, divergence, and strain in a developed submesoscale turbulence field. Geophysical Research Letters 40, 1-6.

Skyllingstad, E., Denbo, D., 1995. An ocean large - eddy simulation of Langmuir circulations and convection in the surface mixed layer. Journal of Geophysical Research: Oceans 100 (C5), 8501-8522.

Soloviev, A. V., 1990. Coherent structures at the ocean surface in convectively unstable conditions. Nature 346 (6280), 157-160.

Sundermeyer, M. A., Skyllingstad, E., Ledwell, J. R., Concannon, B., Terray, E. A., 2014. Observations and numerical simulations of large-eddy circulation in the ocean surface mixed layer. Geophysical Research Letters 41, 7584-7590.

Taylor, G., 1921. Diffusion by continuous movements. Proceedings of the London Mathematical Society 20, 196-212.

Taylor, J. R., Ferrari, R., 2010. Buoyancy and wind-driven convection at mixed layer density fronts. Journal of Physical Oceanography 40 (6), 1222-1242.

Thomas, L., Tandon, A., Mahadevan, A., 2008. Submesoscale processes and dynamics. Ocean Modelling 177, 17-38.

Thorpe, S., 2004. Langmuir circulation. Annual Review of Fluid Mechanics 36 (1), 55-79.

Tkalich, P., 2006. A CFD solution of oil spill problems. Environmental Modelling \& Software $21(2), 271-282$.

Van Roekel, L. P., Fox-Kemper, B., Sullivan, P. P., Hamlington, P. E., Haney, S. R., 2012. The form and orientation of Langmuir cells for misaligned winds and waves. Journal of Geophysical Research: Oceans 117 (5), 1-23. 
Veronis, G., 1959. Cellular convection with finite amplitude in a rotating fluid. Journal of Fluid Mechanics 5 (3), 401-435.

Yang, D., Chamecki, M., Meneveau, C., 2014. Inhibition of oil plume dilution in Langmuir ocean circulation. Geophysical Research Letters 41, 1632-1638.

Yeates, P. S., Gómez-Giraldo, A., Imberger, J., 2013. Observed relationships between microstructure patches and the gradient Richardson number in a thermally stratified lake. Environmental Fluid Mechanics 13 (65), 205-226. 